\title{
Ang "Aswang" at "Tama(w)o" bilang Sinematikong Kaalamang-Bayan at Diyalektika ng Bansa at Rehiyon
} Jay Jomar F. Quintos

\begin{abstract}
Abstrakt
Ang sanaysay na ito ay pagtatangka sa pagbuo at pagbasag sa mga diskurso ng "bayan" at "rehiyon," kaugnay ng "aswang" at "tama(w)o," na nakapunla sa mga pelikula ng Negrenseng direktor na si Richard Somes - "Lihim ng San Joaquin" mula sa Shake, Rattle, and Roll 2 k5 (Monteverde, Monteverde, \& Somes, 2005), Yanggaw (Cinema One Originals \& Richard Somes, 2008), "Tamawo" mula sa Shake, Rattle, and Roll 13 (Monteverde, Monteverde, \& Somes, 2011), at Corazon: Ang Unang Aswang (Calmerin, Kintanar, Samson-Martinez, \& Somes, 2012). Gamit ang anyo ng katatakutan, inilalarawan ng apat na pelikula ang mga tila pangkaraniwang buhay sa hinaharayang laylayan ng bayan kung saan inilalarawan ang antagonistikong "katutubong sistema ng paniniwala," ang tinatanaw na atrasadong buhay sa kanayunan, at ang mapanupil na sistema ng asyenda. Ang mga dalumat na ito ng panahon at espasyo ay ipinapalagay bilang hugpungan ng mga nagdidigmaang proseso $\mathrm{ng}$ dikotomiya at pagkakaiba sa pagitan ng nayon at siyudad, laylayan at sentro, Sarili at Iba, at bayan at rehiyon. Sa huli, sa pamamagitan nang pagbasa sa mga pelikula ni Somes bilang "sinematikong kaalamang-bayan" (filmic folklore), nilalayon ng sanaysay na tasahin at muling hubugin ang mga nilalang na "aswang" at "tama(w)o" bilang balon at artikulasyon ng rehiyonal at pambansang "kasaysayan ng pandama" (history of emotions).
\end{abstract}

Keywords: regional cinema, horror cinema, literary studies, Philippine folklore, Philippines studies 


\begin{abstract}
This essay attempts to construct and deconstruct the discourses of "nation" (bayan) and "region" (rehiyon) vis-à-vis "aswang" and "tama(w)o" embedded in the films of Negrense filmmaker Richard Somes - "Lihim ng San Joaquin" from Shake, Rattle, and Roll 2 k5 (Monteverde, Monteverde, \& Somes, 2005), Yanggaw (Arguelles, Montelibano, Montelibano, \& Somes, 2008), "Tamawo" from Shake, Rattle, and Roll 13 (Monteverde, Monteverde, \& Somes, 2011), and Corazon: Ang Unang Aswang (Calmerin, Kintanar, Samson-Martinez, \& Somes, 2012). Using the horror genre, the four films present the quotidian lives from the nation's peripheries through the depiction of the antagonized "indigenous belief systems," imagined backward-ness of the bucolic landscape, and oppressive hacienda systems. These spatio-temporal dispositifs are deemed to result in the contested processes of the dichotomy and vicissitudes between rural and urban, margin and center, Self and Other, and nation and region. Finally, by considering Somes's films as "filmic folklore," the essay tries to configure and reconfigure the folk creatures "aswang" and "tama(w)o" as cornucopia and articulations of regional and national "history of emotions."
\end{abstract}

Keywords: regional cinema, horror cinema, literary studies, Philippine folklore, Philippines studies

\title{
Plaridel Open Access Policy Statement
}

As a service to authors, contributors, and the community, Plaridel: A Philippine Journal of Communication, Media, and Society provides open access to all its content. To ensure that all articles are accessible to readers and researchers, these are available for viewing and download (except Early View) from the Plaridel journal website, provided that the journal is properly cited as the original source and that the downloaded content is not modified or used for commercial purposes. Plaridel, published by the University of the Philippines College of Mass Communication is licensed under Creative Commons Attribution-NonCommercial-NoDerivatives 4.0 International License (https://creativecommons.org/ licenses/by-nc-nd/4.0/legalcode).

\section{How to cite this article in APA}

Quintos, J. J. F. (2020). Ang "aswang" at "tama(w)o" bilang sinematikong kaalamang-bayan at diyalektika ng bansa at rehiyon. Plaridel, 17(2), 61-97. http://www.plarideljournal.org/article/ang-aswang-attamawo-bilang-sinematikong-kaalamang-bayan-at-diyalektika-ng-bansa-at-rehiyon/ 
Ilang ulit nang binabanggit ang halaga at espasyo ng "rehiyon" sa dalumat ng "sineng pambansa" (national cinema); kung papaanong matutugunan ng mga rehiyon ang puwang at guwang sa hinaharaya at tinatanaw na "bansa" na hindi lamang nakatuntong sa sentro at karatig nitong mga pook. Kung gagalugarin ang kasaysayang pampelikula sa Pilipinas, maliliwanagang mayroon nang mga pelikula mula sa rehiyon noon pa mang 1922. Tingnan, halimbawa, ang El Hijo Disobediente ni Florentino Borromeo na siyang itinuturing bilang kauna-unahang pelikulang Sebwano na nilikha at kinunan sa Mainit, Barili, Cebu (Alburo 1994, p. 161). Magpapatuloy at magiging mayabong ang paglikha ng mga pelikulang Sebwano hanggang sa itinuturing na "Ginintuang Panahon ng Pelikulang Sebwano" (Golden Age of Cebuano Cinema) noong 1950 at 1970. Masusundan ang ganitong saysay ng "pelikulang rehiyonal" (regional cinema) sa iba't iba pang panig ng bansa kung saan itatampok ng ilang direktor ang kultura at buhay ng iba-ibang grupo mula sa mga rehiyon, tulad ng Ifugao (1954) ni Gerardo de Leon, Badjao (1957) ni Lamberto Avellana, at Igorota (1968) ni Luis Nepomuceno. Mahalagang bigyan ng diin ang pagdiriwang sa mga pelikulang binabanggit hindi lamang sa pambansang timpalak kundi maging sa mga internasyonal na film festival (Matilac, Bejarin, \& Jocson, 1994, p. 165). Ngunit pinakamatingkad pa rin na maituturing ang pamumulaklak ng pelikulang rehiyonal-kapuwa sa antas at estetika ng produksiyon at pagkakaroon ng espasyo sa pambansang imahinasyon ng mga manonood at tagatangkilik nito-sa pamamayagpag ng Philippine Independent New Wave Cinema.

Kung imamapa ang umpisa't tunguhin ng Philippine Independent New Wave Cinema, nagsimula ito sa mga huling taon ng dekada nobenta kung kailan sumikat ang paglikha ng pelikula gamit ang teknolohiya ng Digital Video (DV) (dela Cruz, 2010; Tiongson, 2013). Bunsod ng mas demokratikong proseso sa paggawa ng pelikula, naging mas abot-kaya ang paglikha kung kaya't dumami ang bilang nito lalo na ang mula sa labas ng malalaking estasyon at produksiyon sa Maynila. Sa katapusan ng dekada nobenta at pagsisimula ng bagong milenyo, masasabing lumalago at yumayabong na ang ginagawang pelikula ng mga direktor mula sa rehiyon. Bagama't matutukoy na nasa anyo ang mga ito ng maikling pelikula at dokumentaryo, tulad ng Teniente (1999) ni Lawrence Fajardo ng Bacolod at House Under the Crescent Moon (2002) ni Gutierrez Mangansakan II ng Maguindanao, mapapansin ang pag-igib ng mga ito sa kuwento at naratibo ng mga grupo at kultura mula sa mga lugar na kanilang pinanggalingan. Panandang bato naman ang taong 2005 para sa iba't ibang pelikulang rehiyonal na nagkaroon ng oportunidad na maitanghal sa mga lokal at pambansang film festival tulad ng Cinemalaya Independent Film Festival at Cinemanila International Film Festival, nariyan ang maikling pelikulang 
Kultado (2005) ni Lawrence Fajardo na nagtatampok sa hindi pantay na tunggalian ng gahum sa maliit na komunidad sa palengke ng Bacolod at Ang Daan Patungong Kalimugtong (2005) ni Mes de Guzman na nagsasadula sa nakalulumbay na estado ng buhay at edukasyon ng mga batang Kankanaey.

Sa taong 2006, magpapatuloy naman ang pamamayagpag ng mga lokal at pambansang film festival na nagbibigay ng pondo sa mga pelikula mula sa rehiyon. Bagama't nagsisimula na rin sa pagiging institusyong lumililok ng iba't ibang hugis ng gahum ang mga film festival na ito, hindi pa rin matatawaran ang pagkakataong ibinabahagi nila sa mga pelikulang rehiyonal. Sa panahong ito, kapansin-pansin ang pagtatampok ng mga pelikula mula sa rehiyon sa iba't ibang etnolingguwistikong grupo na tila kinalimutan sa pangarap at kasaysayan ng bansa. Tunghayan, halimbawa, ang Batad: Sa Paang Palay (2006) ni Benji Garcia na naglalarawan sa haraya at danas ng isang batang Ifugao na nangangarap magkaroon ng bagong sapatos; at Huling Balyan ng Buhi (2006) ni Sherad Anthony Sanchez na nagsasaysay sa nagsasala-salabit na buhay sa Arakan, North Cotabato ng grupong Lumad na tinawag na "Buhi" (nangangahulugang "buhay" sa Sugbuanong Binisaya), rebeldeng grupo, at sundalo. Bagama’t kapuwa nagkamit ng parangal ang dalawang pelikulang rehiyonal na binabanggit, mahalagang sipatin ang tila pagkahulog ng mga ito sa bitag ng "eksotisismo" at "kabuktutan" (perversion). Magpapatuloy ang pagtatampok sa mga etnolingguwistikong grupo sa pelikulang rehiyonal hanggang sa pagsapit ng 2008, nariyan ang Brutus: Ang Paglalakbay (2008) ni Tara Illenberger na tumutukoy sa isyu ng lakas-paggawa ng mga batang Mangyan at ang Hunghong sa Yuta (2008) ni Arnel Mardoquio na nagsasalaysay sa kalagayan ng grupong Tagakaolo sa Mindanaw.

Sa pagsapit ng 2009, masasabing mas naging bukas ang mga pelikulang rehiyonal sa pagtatampok sa iba pang isyu, kuwento, at paksa. Sa mga maikling pelikulang To Siomai Love (2009) at Ang Katapusang Bagting (2010) ni Remton Siega Zuasola, binibigyan ng lokal na tekstura ang pag-ibig na nakalunan sa Cebu at nagsusuri sa panlipunan at pampolitikang implikasyon ng mga ito. Susundan ni Zuasola ang dalawang maikling pelikulang ito ng Ang Damgo ni Eleuteria (2010) na hango sa maikling kuwento ni Ma. Victoria Beltran na naglalahad sa huling araw ng isang dalagang Sebwana bago ito tumungo sa Germany upang maging mail-order bride. Sa taon ring ito, ipagpapatuloy ni Mes de Guzman ang paglikha ng pelikula tungkol sa danas ng mga grupo mula sa bulubundukin ng Caraballo, partikular na ng mga Isinay sa kaniyang mga pelikulang Ang Mundo sa Panahon ng Yelo (2010) at Ang Mundo sa Panahon ng Bato (2010). Sa Mindanaw, naging masigasig din sa paggawa ng mga pelikulang rehiyonal na tumatalakay sa pang-araw-araw na tunggalian at suliranin ng mga Lumad, Muslim, at 
Dayo sina Arnel Mardoquio, Gutierrez Mangansakan II, at Sheron Dayoc. Tampok sa Sheika (2010) ni Mardoquio ang paglipat ng mag-iinang Tausug mula Sulu patungo sa siyudad ng Davao. Bunsod ng hindi matapos-tapos na digmaan sa Sulu, tumungo sa Davao ang mag-iina sa pag-asang magkaroon ng payapang buhay ngunit lingid sa kanilang kaalaman, kakaharapin nila rito ang iba pang anyo at kulay ng karahasan. Sa Limbunan (2010) naman ni Mangansakan II, tampok ang pakikibaka ng mga babaeng Maguindanaon upang labanan ang kultura ng patriyarka sa panahon pagkatapos ng EDSA People Power 1 noong 1986. Sa Halaw (2010) ni Dayoc, isinasalaysay ang hirap ng buhay ng mga tao sa laylayan ng Mindanao na mas pinipiling subukan ang buhay sa kabilang ibayo. Masusundan ang mga pelikulang Mindanaw na ito ng Ang Paglalakbay ng mga Bituin sa Gabing Madilim (2012) ni Mardoquio, Qiyamah (2012) at Obscured Histories and Silent Longings of Daguluan's Children (2012) ni Mangansakan II, Sonata Maria (2014) ni Bagane Fiola, Women of the Weeping River (2016) ni Dayoc, Daughter of the Three Tailed Banner (2016) at Forbidden Memory (2016) ni Mangansakan II, Tu Pug Imatuy (2017) ni Arnel Barbarona, at Masla a Papanok (2018) ni Mangansakan II.

Bukod sa buhay at haraya ng iba-ibang etnolingguwistikong grupo mula Luzon, Visayas, at Mindanaw, higit na kapansin-pansin din sa pamamayagpag ng mga pelikulang rehiyonal ang mariing pagtatampok sa "kaalamangbayan" (folklore) mula sa nagtatagisang panahon ng kahapon, ngayon, at bukas. Kung hinaharaya ang pelikulang rehiyonal bilang mahalagang elementong tumutugon sa puwang ng bansa, maari din namang iharaya ang kaalamang-bayan bilang mahalagang salaysay na nagpupuno sa bitakbitak na patlang sa pandama at pangangarap ng bansa. Hugpungan ang kaalamang-bayan hindi lamang ng kung ano ang nasa nakalipas kundi maging sa kung ano ang narito at naroon.

Sa Anacbanua (2009) ni Christopher Gozum, litaw na litaw ang katuwiran ng kaalamang-bayan sa pamamagitan ng katutubong panitikan at kultura na naiipit sa nag-uumpugang daigdig ng lokal, pambansa, at migrasyon. Hinahabi naman ni Ray Defante Gibraltar sa Wanted Border (2010) ang katutubong kaalamang-bayan ng mga Panayanon tungkol sa aswang at ang panlipunan at pampolitikang pagpapakahulugan dito mula sa danas ng bansa sa panahon ng kolonyalismo at Batas Militar noong dekada sitenta. Tinatampok naman ni Kanakan-Balintagos (Aureus Solito) ang mga kaalaman, kultura, at paniniwala ng grupong Palawanon sa kaniyang mga pelikula. Sa Busong (2011), litaw na litaw ang katutubong kaalaman-bayan hinggil sa panggagamot sa isang sakit na ginagabayan ng mga elementong lupa, apoy, tubig, at hangin. Sa Baybayin (2012), tinutunton ni KanakanBalintagos ang bakas ng naglalahong kultura tulad ng baybayin na siyang 
susi sa ugnayan ng dalawang magkapatid na babae. Lumikha naman ng isang pinagsama-samang kosmolohiya ng iba't ibang grupo ng Lumad sa Mindanaw at Sulu, animo'y mayroon lamang silang iisang paniniwala, ang Ang Mga Tigmo sa akong Pagpauli (2013) ni Arnel Mardoquio. Sa Debosyon (2013) naman ni Alvin Yapan, isinasadula ang pagtatalaban ng "katutubong kultura" sa pamamagitan ng talinghaga nina Oryol at Daragang Magayon at ng "dayuhang kultura" sa imahen ng Birhen ng Peñafrancia. Bagama't kinikilala naman ni Ara Chawdhury sa Miss Bulalacao (2015) ang bisa ng bituin sa katutubong kaalamang-bayan, tila nagmukhang lutang at espekulasyon lamang ang naratibo hinggil sa buhay ng isang "bayot" na nagdalang-tao. Kung titingnan naman ang Baboy Halas (2016) ni Bagane Fiola, tampok ang "katutubong sistema" sa pamamagitan ng mga hindi maipaliwanag na paniniwala na umiinog sa pang-araw-araw na buhay ng isang pamilyang Matigsalug sa gitna ng kagubatan, na tila kinalimutan ng bansa sa pambansang hinagap at gunita nito. Binabalikan naman ni Christopher Gozum sa kaniyang period film na Dapol tan payawar na Tayug 1931 (2017) ang makasaysayang paghihimagsik sa Tayug ng mga magsasaka. Isinasalaysay ang pelikula sa pamamagitan ng tatlong nagtatalastasang sinulid ng kahapon, ngayon, at bukas.

Kung susuriin ang lawas ng nilikhang pelikula ng mga direktor mula sa rehiyon na umiigib ng naratibo sa balon ng kaalamang-bayan, kapansinpansin ang masikhay na pagsalok ni Richard Somes sa mga kuwentong nagmula sa Panay. Sa sumisibol na tradisyon ng pelikulang rehiyonal sa bansa, masasabing nakaugat ang karamihan sa mga pelikula ni Somes sa pinagmulan at kinalakihan niyang lugar sa Negros Occidental; litaw na litaw sa mga ito ang bakás at dalumat ng katutubong kaalamang-bayan. Maituturing na supling si Somes sa pamana ni Peque Gallaga sa pelikulang Hiligaynon. Kung babalikan, mataos ang inilaang oras at panahon ni Gallaga upang sanayin at turuan sa paggawa ng pelikula at pagpapayabong ng pelikulang Hiligaynon ang mga kapuwa niya Ilonggo (Groyon, 2014; Lumbera, 2013). Bukod pa rito, mababanaag din ang impluwensya ng mga kaalaman at paniniwala sa Panay sa ilang pelikula ni Gallaga tulad ng Oro, Plata, Mata (1982), Aswang (1990), Sa Piling ng Aswang (1999), at iba pang episodyo sa serye ng Shake, Rattle, and Roll (SRR). Maaaring gawing lunsaran, kung gayon, ang realidad na ito sa anyo ng karamihan sa mga pelikula na nilikha ni Somes: nilililok at hinuhubog ng mga nauna nang pelikula ni Gallaga na nauna nang umigib ng kuwento at naratibo sa batis ng kaalamang-bayan sa Panay.

Bagama't nagsimula bilang production designer sa mga pelikula ni Erik Matti (Kotzathanasis, 2018), sa kasalukuyan ay mayroon nang 14 pelikula sa pangalan ni Somes bilang direktor, kabilang na dito ang dalawang episodyo 
mula sa Shake, Rattle, and Roll (SRR) at isang maikling pelikula. Kung pagbabatayan ang listahan ni Somes, hindi maikakaila ang pag-indayog niya sa paggawa ng pelikula kapuwa sa produksiyong mainstream at independent. Sa puntong ito, malay na gagamitin ang problematikong tambalan ng mainstream at independent upang higit na maging malinaw kung saan o anong pelikula nagkaroon ng mas malayang pagharaya ang direktor kompara sa produksiyong higit na ginagabayan ng malalaking prodyuser. Gayundin, bagama't kinakailangan nang basagin ang mga kalakip na simplistiko at reduktibong kahulugan ng mga katawagan, gagamitin pa rin ang mga ito sa kasalukuyang pag-aaral upang palitawin at mapatingkad ang diskurso hinggil sa realidad ng mga pelikulang may pondo mula sa malalaking prodyuser at ang pakikipagtalastasan nito sa diskurso ng pelikulang rehiyonal. Sa ilang taon na pamamayagpag ng Philippine Independent New Wave Cinema, naging saksi na ito sa mga pelikulang nahuhulog kapuwa sa katawagan ng mainstream na produksyon at pelikulang rehiyonal.

Mula sa 14 pelikulang nakalakip sa pangalan ni Somes bilang direktor, layon ng kasalukuyang pag-aaral na suriin ang ilan sa kaniyang piling pelikula na matiim na umiigib sa "katutubong kaalamang-bayan" ng mga Panayanon. Mahihiwatigan na mahahati sa dalawang mukha ang anyo ng mga pelikula ni Somes: ang una'y nahuhulog sa anyo ng pelikulang krimen at kung minsa'y naglalarawan sa urbanisado at modernisadong buhay sa lungsod habang ang pangalawa'y nagsasaysay sa mga nilalang sa katutubong kaalamangbayan ng Panay. Sa kasalukuyang pag-aaral, higit na pagtutuunan ng pansin ang pangalawang mukha ng mga pelikula ni Somes na nagtatampok sa mga nilalang ng aswang at $\operatorname{tama}(w)_{o}$ lalo na't higit na matingkad sa mga ito ang sensibilidad ni Somes bilang direktor ng pelikulang rehiyonal. Apat ang piniling pelikulang susuriin sa pag-aaral: "Lihim ng San Joaquin" mula sa SRR $2 k 5$ (2005), Yanggaw (2008), “Tamawo" mula sa SRR 13 (2011), at Corazon: Ang Unang Aswang (2012). Kung mapapansin, kapuwa binibigyan ng hugis at anyo ng katatakutan ang apat na pelikula. Hindi rin maitatanggi na nagkakaiba-iba ang moda at proseso ng produksiyon ng mga ito - ang dalawa'y bahagi ng matagumpay na serye ng pelikulang katatakutan na pinondohan ng isa sa pinakamalaking film outfit sa bansa, at ang dalawa naman ay pinondohan ng maliliit na sangay (Cinema One Originals at Skylight Films) ng isa sa pinakamalaking korporasyon ng media sa bansa. Sa ganitong konteksto, may integral na bahagi ang realidad hinggil sa proseso ng produksiyon ng mga pelikula lalo na sa anyo nitong katatakutan at motibo ng mga prodyuser na magkaroon ng sapat at higit na kita.

Sa pag-aaral sa apat na binabanggit na pelikula ni Somes, mahalagang intindihin na hindi lamang karakter ang aswang at tama(w)o rito-sila'y nagsisilbi ring estetika, talinghaga, pagkakataon, at paggambala. Kung 
tinatanaw na bahagi ng kaalamang-bayan na itinatampok sa pelikula ang mga binabanggit na nilalang, maaaring mahulog ang mga ito sa kategorya ng "sinematikong kaalamang-bayan" (filmic folklore). Ang mga siwang na pinupunan ng kaalamang-bayan, marahil sinematikong kaalamangbayan kung susundan ang mga pelikula ni Somes, ang siyang mahalagang sangkap sa pagsasalaysay ng damdamin at emosyon ng bansa. Sa isang bansa-na dapat ay tinitingnan lagpas sa mapanupil na heograpikong imahen at batayan - na binubuo ng watak-watak na mga pulo, iba-ibang kultura at tradisyon, halo-halong paniniwala at pananampalataya, nagiging makabuluhan ang pagtanaw sa diskurso ng bansa bilang isang kultural na espasyo na hindi mawari ang hanggahan, ritmo, saklaw, at timbang dahil sa katangian nito na animo'y talaban (hybrid) ng nagbabanggaang kultura (Bhabha, 1990). Sa bahaging ito nagiging mahalaga ang pag-iral ng kultura mula sa iba-ibang daluyan at lunduyan tulad sa sining ng arkitektura, musika, sayaw, panitikan, at pelikula, sapagkat sa mga ganitong anyo sumisilip ang "paggambala" (interrupting the nation) ng mga kultura mula sa laylayan laban sa dakilang pagpapakahulugan sa naratibo ng bansa na lagi't lagi'y nakasandig sa mapanupil na sentro. May dalawang puwersang nakapaloob sa proseso ng paggambala: una, ang ginambala at pangalawa, ang nanggagambala. Mahihiwatigang nagdudulot ng paghinto sa siklo ng paggalaw ang paggambala, ngunit pansamantala lamang ito sapagkat muli itong papalaot upang kumilos at gumalaw (Barbaza 2017, p. xix). Animo'y isang siklo ang paggambala na umiikot-ikot lalo na sa hinaharayang komunidad na pinapagana hindi lamang ng magkakatulad at iisang gawain kundi maging ng mga puwersang pinapanday ng pagbabahagi at pagkakakilanlan ng bawat indibidwal at indibidwalidad dito (Nancy 1991, p. 9). Nagiging makatwiran, kung gayon, ang paggambala sa monolitikong nosyon ng "bansa" lalo na sa antas ng mga salaysay at kaalaman nito. Sa kasalukuyang pag-aaral, pangunahing tuon ang pagsusuri sa talastasang nililikha at digmaang pinasisiklab ng "aswang" at "tama(w)o"bilang mga "sinematikong kaalamang-bayan" sa dalumat at diyalektika ng nagtatalabang diskurso ng "paggambala" sa pagitan ng mga puwersa ng "rehiyon" at "bansa."

\section{Hinggil sa "Salaysay ng Damdamin" at "Sinematikong Kaalamang-Bayan"}

Mapanghikayat ang tinig at litanya ni Resil Mojares (2002) ukol sa muling pagbibigay-tuon sa binabanggit ni Lucien Febvre na "salaysay ng damdamin" (histoire des mentalites). Binabanggit ni Mojares na kung ang bansa ay isang lunan na mayroong kaluluwa, masidhi ang pangangailangan ukol sa pag-aaral sa karanasan nito sa kaniyang buhay-pandama. Sa ganitong pagpapalagay, nagkakaroon ng pagkiling sa muling pagbalik sa kaalamang-bayan na 
maaaring maging balon at batis na pagkukunan ng pangarap, pagnanasa, at damdamin ukol sa binubuong larawan ng bansa. Ginamit na halimbawa ni Mojares ang tampok na kaalamang-bayan sa Laguna na "Alamat ni Mariang Makiling" bilang panimulang pigura sa pagbuo ng "salaysay ng damdamin" ng bansa. Sa imahinasyon ni Mojares, taglay ni Mariang Makiling ang bakás, bahid, at tanda ng iba-ibang ideya at konseptong ipinapataw sa imahen ng bansa. Sa mga panitikang bayan tulad sa epiko, larawan siya ng pakikidigma at kalakasan, isa naman siyang tumatangis at nanunumbat na alamat sa makaEuropeong guniguni, at sa kontemporanyong pagpapakahulugan, larawan siya sa mga tula bilang babaeng ginahasa at pinagsamantalahan. Animo'y dumadaloy, minsa'y umiikot, at karaniwa'y nagbabago-bago ang timbang at bigat ng paggambala at paglalarawan kay Mariang Makiling bilang salaysay ng damdamin ng bansa. Mula rito, mababanaag ang pagdidiin ni Mojares sa dalumat ng aktibo at malay na "paghihintay" kay Mariang Makiling na makatutulong sa pagbuo sa kolektibong karanasan at imahen ng bansa.

Kung batis na pinagkukunan ng mga pelikulang rehiyonal ang kaalamang-bayan at tila ilog naman na nagiging daluyan ng kaalamangbayan ang midyum ng pelikula, maaari nang usisain ang dalumat ng pelikula hindi na lamang bilang kulturang popular kundi bilang bahagi na rin ng mismong kaalamang-bayan. Sa imahinasyon ni Juwen Zhang sa kaniyang akdang "Filmic Folklore and Chinese Cultural Identity" (2005), ${ }^{1}$ hinaharaya ang pelikula hindi na lamang sa punto de bista ng sining na dumaraan sa mekanikal na proseso nang paghahabi-habi ng ilaw, disenyong pamproduksiyon, tunog, at musika mula sa kuwadro patungo sa lente ng kamera, kundi ito'y kabahagi na rin sa mismong lawas ng kaalamang-bayan. Sa pagpapakahulugan ni Zhang (2005) sa sinematikong kaalamang-bayan (filmic folklore):

Filmic folklore, by definition, is an imagined folklore that exists only in films, and is folklore or folklore-like performance that is presented, created, or hybridized in fictional film. Taken out of the original (social, historic, geographic, and cultural) contexts, it functions in similar ways to that of folkloric films. Filmic folklore imposes or reinforces certain stereotypes (ideologies), and signifies certain meanings identified and consumed (as "the truth") by a certain group of people. The folklore in filmic folklore may appear as a scene, an action, an event, or a storyline (plot), and in verbal or non-verbal form. (p. 267)

Mahalagang sipatin ang paggamit ni Zhang (2005) sa katawagang hinaharayang kaalamang-bayan (imagined folklore) bilang paglalarawan 
sa sinematikong kaalamang-bayan (filmic folklore). Sa hinuha ni Zhang, hindi tuwirang kaalamang-bayan ang taglay ng sinematikong kaalamangbayan kundi haraya lamang na isinasapelikula. Umiiral ito nang walang ugat at konteksto, labas sa pinagmumulan nitong lipunan, kultura, at kasaysayan. Sa isang banda, produkto itong iniluluwal ng nagbabanggaang imahinasyon ng mismong manlilikha at kaalamang-bayang pinaghalawan habang sa kabilang banda, tulad ng tradisyonal na pagtingin sa kaalamangbayan, nagiging makabuluhan din ang "sinematikong kaalamang-bayan" sa pamamagitan ng paglikha nito ng diskurso at rekurso hinggil sa mga partikular na isyu, paksa, at panlipunang agam-agam.

Maaaring ipagpalagay na naiba ang dalumat ng sinematikong kaalamang-bayan (filmic folklore) sa poklorikong pelikula (folkloric film). Tumutukoy ang poklorikong pelikula (folkloric film) sa mga pelikulang naglalaman at naglalahad ng dokumentasyon ng mismong naratibo ng kaalamang-bayan mula aktuwalidad patungo sa lente ng kamera. Kalimitan, dokumentaryo ang anyo nito na siyang direktang nagrerekord ng aktuwal, realidad, at consequential na paksain ng kaalamang-bayan. ${ }^{2}$ Kakaiba ito sa sinematikong kaalamang-bayan (filmic folklore) na ang tuon ay ang pagtatampok sa mga elemento ng kaalamang-bayan at saka paghulma rito upang umakma sa hugis ng naratibo ng pelikula. Habang ang poklorikong pelikula ay nakatuon sa paglalarawan sa tuwirang imahen ng mga kaalamangbayan, ang "sinematikong kaalamang-bayan" ay naglalayong lumikha ng kuwento na umiigib sa balon ng kaalamang-bayan.

Sa pagtataya ni Zhang (2005), hindi sinasalamin ng sinematikong kaalamang-bayan ang mismong kultura at kasaysayan na pinanggalingan ng kaalamang-bayan na hinahalaw, kakaiba sa poklorikong pelikula na hayagang nagpapakita ng katapatan sa inirerekord na kaalamangbayan. Tumutukoy ang sinematikong kaalamang-bayan sa paglalapat ng interpretasyon, at maging sa kasanayan hinggil sa pagtibag, pagbasag, at muling pagbuo sa kaalamang-bayan, gamit ang lente ng kamera. Tulad ng naunang espekulasyon, itinatawid ng sinematikong kaalamang-bayan ang kaalamang-bayan mula sa kahapon patungo sa ngayon at hanggang sa bukas. Ngunit, may paalala si Zhang ukol sa paraan ng pagbasa sa sinematikong kaalamang-bayan. Sa halip na magsilbing konteksto na magsusuri sa nakalipas na makatutulong sa pagmumuni-muni sa kung ano ang narito at nakahapag, higit na nararapat usisain ang proseso at ugnayan sa pagsipat, pagbasa, at pagtampok ng mga kaalamang binibigyang buhay sa kuweba ng telon at pelikula. Maaaring sabihin na lumilikha ang sinematikong kaalamang-bayan ng bagong kaalaman ukol sa kasalukuyan na pinapanday ng nagkakaiba-iba at nagsasala-salabid na mga interpretasyon at kahulugan. 
Sa kasalukuyang pag-aaral, tinatanaw ang aswang at tama(w)o sa mga pelikula ni Somes bilang salaysay ng damdamin at sinematikong kaalamangbayan. Masasabing sisidlan ng artikulasyon ang mga ito na siyang nagiging batingaw at alingawngaw ng mga bantas at panuto hinggil sa diyalektika ng pelikulang rehiyonal at pelikulang pambansa, laylayan at sentro, at rehiyon at bansa. Sa ganitong pagsipat, maaari nang ihabi ang talinghaga ng aswang at tama(w)o, kalakip ang kinakatawan nitong diskurso hinggil sa nagtatalastasang retorika ng rehiyon at bansa, sa mas malawak na balarila at dalumat ng hinaharayang mukha at hugis ng bansa. Sa bahaging ito, mahalaga ring balikan ang binabanggit na paggambala sa bansa (interrupting the nation) sa pamamagitan ng sinematikong kaalamang-bayan na binibihisan ng katatakutan - ang anyong may kakayahang magnilay sa nagsasalikop na daigdig ng prekolonyal at kolonyal. May kakayahang lumikha ng takot at agam-agam ang Iba sa Sarili, ang rehiyon sa bansa, ang nasyonalismo sa nag-iiba-ibang identidad mula sa rehiyon.

\section{Aswang}

Tatlong pelikula ni Richard Somes ang masasabing nagtatampok sa aswang bilang tanyag na nilalang na bahagi sa kaalamang-bayan ng Panay. Bagama't nag-iiba-iba ang paglalarawan at pagpapakahulugan ng tatlong pelikula_"Lihim ng San Joaquin" mula sa SRR 2K5 (2005), Yanggaw (2008), at Corazon: Ang Unang Aswang (2012) —sa pinagmulan at motibasyon ng karakter ng aswang, nagkakasundo naman ang lahat ng ito sa imahen ng aswang bilang nilalang na sumisipsip ng dugo at kumakain ng lamang-loob ng tao sa mga sandaling kumakagat na ang dilim.

Tila isang buslong sisidlan ng maraming pagpapakahulugan ang nilalang na aswang sa aralin at lipunang Filipino. Sa Mindanaw, tila maihahalintulad sa larawan ng busaw/tarabusaw/talagbusao ang imahen ng aswang. May paniniwala ang mga Bukidnon Manobo ukol kay Talagbusao na bahagi ng pangkat ng mga diyos ng pakikidigma; diyos ito na hayok sa dugo at sumasapi sa mga tao na kaniyang pipiliin (Dadole, 1986). Sa pag-aaral naman ni Rafael Tianero (2002) ukol sa paniniwala ng iba pang pangkat ng Manobo, masasama ang siyamnapu't pitong bahagdan ng mga busaw na kalimitang pumapatay at kumakain ng tao.

Kung pagbabatayan naman ang pagtanaw sa Kabisayaan, malalim din ang pinag-iigibang balon ng paniniwala ukol sa aswang. Mahihinuhang mayroon nang sinasandigang paniniwala hinggil dito ang sinaunang pamayanang Bisaya, na marahil bunga ng heograpiko at kultural na maling pagtangi sa pagitan ng nagkakaiba-ibang pangkat at populasyon. Sa mga tala ni Miguel de Loarca sa kaniyang Relacion de las Yslas Filipinas (1582), may ilang impormasyon tungkol sa mga nilalang na kumakain ng dugo't laman ng 
tao. May obserbasyon si Loarca hinggil sa paniniwala sa mga patay, laganap dito ang kuro-kuro ng mga "Pintados" tungkol sa mga "mangalos" o ang nilalang na tila duwende (goblin) ang itsura at kumakain ng lamang-loob ng mga batang namamatay sa Kabisayaan (Loarca, 1582). Ang paglalarawan ni Loarca sa mangalos, bunga na rin ng katangian nitong kumakain ng lamangloob ng tao, ay maaaring ikabit sa dalumat ng aswang. Hindi rin ito nalalayo sa mismong pagpapakahulugan ni Francisco Ignacio Alcina sa kaniyang Historia de las Islas e Indios de Bisayas (1668). Sa pagpapalagay ni Alcina, may paniniwala ang mga tao sa Kabisayaan ukol sa aswang, aluk, o unglu, ang nilalang na kumakain ng lamang-loob ng may sakit at mahihinang indibidwal. Dagdag pa ni Alcina, isang malaking insulto para sa mga tao sa Kabisayaan kung matatawag silang aswang dahil nangangahulugan ito ng pagiging kabilang sa mababang antas at uri sa komunidad.

Kung sasangguni naman sa mga sumunod na pag-aaral ng mga lokal na mananaliksik, mapapansin na tila mas kultural ang pagdulog na ginamit ng mga ito. Sa espekulasyon ni Alicia Magos (2005), ang dalumat ng aswang ay maaaring nagmula sa mga karakter sa mga sugidanon (epiko) sa Panay. Ang karakter ni Paglambuhan ay tinatawag na aswang sa isa sa mga episodyo ng Hinilawod dahil sa pangongolekta nito ng mga buto at bungo ng kalabang napupuksa niya (Magos, 2005). Tanda ng pagiging isang magiting na mandirigma ang gawing ito ni Paglambuhan. Sa pagtanaw ng mga editor ng Antolohiya ng mga Panitikang Asean: Mga Epiko sa Pilipinas (Castro, Antonio, Melendez-Cruz, Mariano, \& Makasiar-Puno, 2009), isang aswang ang karakter ng hari ng araw na si Saragnayan sa sugidanong Labaw Donggon ng mga Panay Bukidnon ${ }^{3}$. Sa isang bahagi ng sugidanon, kinatatakutan ng mga anak ni Labaw Donggon na sina Asu Mangga at Buyung Baranugun ang pangyayaring maaaring kainin ni Saragnayan ang kanilang ama. Sa talababa ng mga editor, inihahayag na "pinaniniwalaang si Saragnayan ay isang aswang o mangkukulam na nangangain ng mga biktima” (p. 154).

Umuulit ang taguri na aswang sa isang karakter sa isa pang sugidanon ng mga Panay Bukidnon na Tikum Kadlum (Caballero \& CaballeroCastor, 2014). Inawit nina Federico "Tuohan" Caballero at Teresita "Abyaran" Caballero-Castor at inirekord at isinalin naman ni Alicia Magos ang sugidanong binabanggit. Dito, itinuturing ang karakter ni Buyong Makabagting bilang aswang o tagubalbal. Sa talababa ng tagasalin, sinasabing sa konteksto ng epiko, ang aswang o tagubalbal ay isang nilalang na maari ring isang 'buyong,' isang marangal na tao sa komunidad na kilala rin sa pagiging magiting na mandirigma na nakatikim o nakakain na ng laman-loob ng tao (p. 11). Mahalagang sipatin sa puntong ito ang pagpapakahulugan ni Magos sa aswang na ikinakabit din sa tagubalbal. Tila hindi sumusunod sa dikta ng mga naunang dayuhang historyador ang pagpapalagay na ito ni 
Magos dahil nagiging sisidlan ng ibang pagpapakahulugan ang karakter ng aswang at hindi nalilimitahan sa kasamaan at kabutihan lamang. Kumakain ito ng lamang-loob ng tao sa isang banda, ngunit isang marangal at magiting na mandirigma naman ito sa kabilang banda. Maaari ring pag-isipan na, marahil, ang pagkain ng lamang-loob ng tao ay hindi itinuturing na masama sa sinaunang kultura. Mula sa mga inilatag na katangian at larawan ng aswang, mapapansin na bitbit nito ang supling ng imahen ng prekolonyal at kolonyal na daigdig. Batis din na pinag-iigiban ng pagpapakahulugan sa aswang ang mga naratibo mula sa katutubong sistema ng paniniwala ngunit binibihisan na ito ng anyong katatakutan at kakila-kilabot sa kolonyal na naratibisasyon. Kung gayon, tila naiipit sa dalawang nagbabanggaang diskurso ang dalumat ng aswang sa kultura at lipunang Filipino.

Sa tatlong pelikula ni Somes na sinusuri, tanging ang "Lihim ng San Joaquin" mula SRR $2 K 5$ (2005) ang siyang tuwirang sumusunod sa kolonyal na pagpapakahulugan sa aswang. Kung babalikan ang banghay ng pelikula, itinatampok nito ang kuwento ng isang lalaki at buntis niyang asawa na tumakas sa kanilang mga magulang at piniling mamuhay sa isang malayo at tagong probinsiya. Lingid sa kaalaman ng mag-asawa, ang nakatira pala sa nilipatan nilang pook ay mga aswang na mahilig kumain ng sariwang bata na nasa sinapupunan pa lamang. Sa pagwawakas ng kuwento, susubukang puksain ng lalaki ang lahat ng makasasagupa niyang aswang nang sa ganoon ay maprotektahan at makaligtas ang kaniyang asawa at magiging anak. Sa pelikulang ito, hinaharaya ang karakter ng aswang bilang nilalang na kakaiba sa tao at nabubuhay upang palaganapin ang kanilang angkan. Sumusunod ang naratibo ng pelikulang ito sa naunang episodyo na "Aswang" ng SRR 2 (1990) na nilikha nina Peque Gallaga at Lore Reyes.

Tila sumusunod naman ang Yanggaw (Arguelles, Montelibano, Montelibano, \& Somes, 2008) sa naratibo ng "Lihim ng San Joaquin" (Monteverde, Monteverde, \& Somes, 2005) lalo na't nagsimula ang kuwento nito sa pagkakasakit ng isa sa mga bidang karakter na si Amor. Buhat nang pakikipista sa ibang bayan, nagkaroon ng impeksiyon si Amor na hindi mapangalanan ng mga albularyo. Mula rito'y dali-dali siyang umuwi mula sa siyudad na pinagtatrabahuhan patungo sa liblib na baryo kung saan nananahan ang kaniyang pamilya. Habang dumadaloy ang naratibo'y lalong lumulubha ang hindi mapangalanang sakit ni Amor hanggang sa kalaunan, mahahantad na nagiging halimaw pala ito tuwing sasapit ang gabi at saka humahanap ng mga nilalang tulad ng hayop at tao na maaari niyang kainin. Sa kuwento, naiipit ang pamilya kung ano ang gagawin kay Amor-hahayaan na lamang ba itong pumuksa ng ibang tao upang mapanatili itong buhay o buhay ng iba't ibang miyembro ng pamilya ang hahayaan nilang kitlin ni Amor? Sa imahinasyong Ilonggo, may paniniwala hinggil sa yanggaw o 
ang pagkakaroon ng laway mula sa isang aswang na maaaring magdulot ng pagiging aswang din ng kung sinong makakakuha nito. Sa pelikula, hindi malinaw kung totoong may hindi mapangalanang sakit si Amor o nahawaan ito ng pagiging aswang mula sa pistahang dinaluhan.

Naiiba naman ang banghay ng pelikulang Corazon: Ang Unang Aswang (Calmerin, Kintanar, Samson-Martinez, \& Somes, 2012) sa dalawang naunang pelikula ni Somes. Hindi ang paghawa ang ugat ng pagiging aswang ni Corazon kundi ang pagkawala ng pananalig at pananampalataya niya sa Kristiyanismo. Naganap ang naratibo ng pelikula sa yugto ng kasaysayan na pinaghaharian ng sigalot at sistemang piyudal. Bunsod ng pagkamatay ng kasisilang pa lamang na sanggol ni Corazon, tuluyan na nitong itinakwil at isinumpa ang Kristiyanong paniniwala. Upang madagdagan pa ang panghahamak at pang-iinsulto sa nakagawiang pananampalataya, kinain ni Corazon ang kaniyang sanggol at magmula noon, isinumpa na niya ang lahat ng isisilang na sanggol sa kanilang bayan. Sa daloy ng panahon, isaisang papatayin at kakainin ni Corazon ang bawat sanggol na nagdudulot sa pagbabago ng kaniyang anyo patungo sa isang nakatatakot at nakakikilabot na halimaw. Kung susumahin, tila mapanganib ang kahulugang inihahayag ng pelikula lalo na sa antas ng pagbibigay kasaysayan sa aswang. Ipinapakita sa pelikula na ang aswang ay nilalang na tumiwalag sa Kristiyanismo bunga ng kabiguang matanggap ang kanilang mga dinarasal at hinihiling.

Mula sa tatlong pelikula tungkol sa nilalang at karakter ng aswang, lumilitaw ang dalawang diskurso na maaaring maging daluyan ng talastasan hinggil sa dalumat ng bansa at rehiyon: una, ang diskurso hinggil sa seksuwalidad ng aswang at ang kaugnayan nito sa anyo ng katatakutan at sa imahen ng bansang naiipit sa prekolonyal at kolonyal na daigdig; at pangalawa, ang diskurso hinggil sa lunan, lunggati, at katatakutan ng mga nasa laylayan ng bansa kung saan nakapaloob ang sistema ng moralidad, relihiyon, at kinagisnang paniniwala sa espasyo ng pastoral, rural, at asyenda na malimit kumikiling sa pagsasamantala at panunupil.

Kung babalikan ang imahen ng mga bidang aswang sa Yanggaw at Corazon, tila nahuhulog sa iisang larawan ang itsura nito: magandang babae, mahaba ang buhok, at kayumangging kaligatan ang kulay. Ang mga bidang babae bilang aswang, kapuwa sa dalawang pelikula, ay sumusunod sa ganitong paglalarawan. Samantala, sa "Lihim ng San Joaquin," (Monteverde, Monteverde, \& Somes, 2005) lalaki ang siyang punong lider ng mga aswang ngunit kapansin-pansin ang paglalarawan sa babae bilang aswang na tila nakulong lamang sa imahen ng pagiging dekorasyon at gumaganap sa tungkuling nakasandig sa sinasabing batas at kaayusan ng patriyarkal na sistema-gumagawa ng pagluluto, paghahanda ng pagkain, at pagiging mesiyas at tagaaliw ng mga lalaki. Sa puntong ito, sumisilip ang nililikhang 
diskurso ng mga pelikula tungkol sa tinatawag ni Herminia Meñez (1999) na "pemenisasyon ng halimaw" (p. 87) na maaari raw matunton sa impluwensiyang hatid ng mga dayuhang Espanyol.

Maiuugnay ang konstelasyong nabuo hinggil sa aswang, babae, at bansa sa naunang pag-aaral ni Raul Pertierra (1983) na nagtampok sa dalumat ng "asuang complex" (p. 320) na tumutukoy sa mga banta sa kaayusan ng lipunan. Gamit ang ilang naunang tala tulad ng mga akda nina Frank Lynch (2004) at Maximo Ramos (1971), ipinapalagay ni Pertierra (1983) na ang mga aswang ay idyoma ng babala at takot sa antas ng moralidad at pagiging malay. Ang mga imahen daw ng aswang ay hindi kailanman kinakailangang tularan ng mga tao sapagkat ang mga ito ay nagmula sa labas ng lipunan. Walang pakialam ang mga aswang sa pinapahalagahang kabanalan at birtud na karapat-dapat panatilihin at pagyabungin, halimbawa nito ang kawalan daw nila ng konsepto ng reciprocity o utang na loob. Dagdag pa ni Pertierra, ito rin ang birtud na hindi dapat alisin ng kababaihan bilang miyembro at huwaran sa lipunan:

Women, as members and reproducers of society must also conform to the rules of reciprocity, but their primary orientation seldom requires public validation of reciprocity and in many cases women are seen to restrict its application to the domestic context. Women operate in a context where reciprocity and exchange are so implicitly assumed that it is unnecessary to re-state its basis publicly. (p. 335)

Akma ang pagpapakahulugan ni Pertierra (1983) sa paglalarawan ni Somes sa imahen ng aswang sa kaniyang tatlong pelikula-tagalabas sa kaayusan ng lipunan na tumataliwas sa pamantayan nito. Taglay ng mga karakter sa "Lihim ng San Joaquin," Yanggaw, at Corazon: Ang Unang Aswang, partikular na ang mga babaeng aswang, ang katangian tulad ng kumakain ang mga ito ng hilaw na pagkain, pumupuksa ng tao kahit na kaanib sa pamilya (marahil, bahagi ng "damaged cultures" sa bansa), at hindi pagganap sa mga nakaatang na tungkulin. Sa obserbasyon ni Pertierra, ang mga babae na sumusunod sa gawi at kilos ng aswang ay maaaring mahulog sa bitag ng "asuang complex" (pp. 330-333). Sa puntong ito, nararapat baklasin ang pagsandig at pagkapit ng paniniwala ni Pertierra sa estruktura ng lipunan. Tila umaayon lamang sa sinasabing kaayusan ng lipunan ang pananaw na ito at naisasantabi ang pangangailangan na wakasan ang mga kontradiksyon na nakapaloob dito. Kinakailangan ding baklasin ang mga birtud na binabanggit lalo na't kung susumahin, ito ang mismong pinagmumulan ng mga agam-agam sa lipunan. Hindi rin naaayon ang paglalarawan ni Pertierra sa lahat ng sumusubok na hamunin ang lipunan 
bilang aswang. Sumusunod ito sa kolonyal na pagtingin sa aswang bilang tagalabas na nagtutulak sa komunidad upang maging bitak-bitak, watakwatak, at basag.

Mahalagang sipatin sa puntong ito ang pagtingin ng katutubong sistema ng paniniwala sa estrukturang pangkultura at panlipunan hinggil sa kasarian. Masasabing hindi nakasandig ang realidad nito sa kung ano o sino ang mas may hawak ng gahum sa pagitan ng babae at lalaki. Mababatid mula sa iba-ibang etnograpiya at tala sa Kabisayaan ang pagkakapantaypantay ng pagtingin sa kasarian. Tingnan, halimbawa, ang paniniwala ng mga Panayanon sa penomenon ng mga ma-aram na tumutukoy sa henerikong katawagan sa babaylan, sirhuano, manogbulong, at iba pa. Mahihinuha na hindi lamang nakakulong sa iisang kasarian ang pagiging ma-aram sapagka't ito'y katawagang sumasakop sa kahit na anong kasarian (Magos, 1992, pp. xi-xii). Kung gayon, maipagpapalagay na hindi gaanong binibigyan ng masusing halaga ang tambisan ng gahum sa larang ng kasarian sa katutubong sistema ng paniniwala. Masasabi rin na kaakibat ng kolonyalismong Espanyol ang pagpapalaganap ng dominanteng ideolohiya ng Europeong patriyarka sa sistema ng kasarian sa mga nasakop na bansa tulad ng Pilipinas. Sa obserbasyon ni Lilia Quindoza Santiago (1997), masasabing nagmula ang ugat at estruktura ng kulturang patriyarkal sa dapithapon ng kolonyalismong Espanyol. Ang pag-iral ng patriyarka ay mauugat sa wikang bitbit ng mga mananakop. Kung susuriin, ang pag-iral ng wikang Espanyol sa bansa ang siyang hudyat ng pag-uuri at pagtatakda ng kaibahan sa kasarian ng babae at lalaki. Kung sa wikang Espanyol, matatagpuan ang dalumat ng el at ella na tumutukoy sa lalaki at babae, sa mga wikang laganap naman sa bansa bago ang pananakop, mahihiwatigan na walang ibinibinyag na kasarian sa mga panghalip. Sa ganitong pagbasa, ang kasarian ay hinaharaya bilang salik na hindi gaanong pinagtutuunan ng pansin sa katutubong sistema ng paniniwala (Santiago, 1997).

Kung babalikan ang naratibo ng tatlong pelikula ni Somes hinggil sa aswang, prominente ang "pagbabanyuhay" (pagbabagong anyo ng buhay) ng mga karakter mula sa pagiging tao patungo sa pagiging aswang. Tulad ng naunang nabanggit, kapuwa magandang babae, mahaba ang buhok, at kayumangging kaligatan ang kulay ang katangian ng mga babae sa Yanggaw (Arguelles, Montelibano, Montelibano, \& Somes, 2008) at Corazon: Ang Unang Aswang (Calmerin, Kintanar, Samson-Martinez, \& Somes, 2012). Ngunit sa pagsapit ng gabi, nagbabago ang itsura at tekstura ng balát ng mga babaeng ito patungo sa nakatatakot at nakakikilabot na halimaw. Animo'y sinasapian at nilulukob ang katawan ng babae patungo sa isang aswang na sumisipsip ng dugo at kumakain ng laman ng tao. Sa ganitong konteksto, umaalingawngaw ang bakas ng katutubong paniniwala hinggil sa sapi. 
Kung papansinin, maihahalintulad ang penomenon nang pagiging aswang sa pelikula ni Somes sa realidad ng mga ma-aram (babaylan/babaylanes) hinggil sa pagsapi sa mga ito ng "surog" (gabay na kaluluwa) na maaaring tawagin sa pagsasagawa ng mga ritwal at iba pang nakaatang na tungkulin sa komunidad (Magos, 1992). Sa sugidanong Hinilawod: Humadapnon, may pag-aatubili ang babaylan/ma-aram na si Hugan-an sa pag-awit bunsod ng tuaw o tuhaw, ang pagtawag sa mga kaluluwa na sinasamo kahit na wala namang mahalagang ritwal na dapat isagawa (Jocano, 2000). Pagsusumamo ni Hugan-an sa simula't umpisa ng sugidanon: "Suyung-suyung pay, pamlang, kun katuod may dalongdong" (p. 5) [Come, O spirit friends, if my powers are trusthworthy]. Mahihiwatigan, batay sa kontekstong ito, ang mataas na pagpupugay ng "katutubong sistema ng paniniwala" sa pagsapi ng kaluluwa sa ma-aram. Ngunit mapapansin ang pagbabago nito pagdating ng kolonyalismong Espanyol, tila nagkaroon ng demonisasyon sa ganitong mga paniniwala: ang mga anyo ng kaluluwa ay kinakailangang sikilin at patahimikin sa pamamagitan ng krusipiho at agwa bendita. Animo'y kaluluwa ang sumasapi sa mga aswang na katakot-takot at kakila-kilabot at kinakailangang puksain at patahimikin.

Sa panahon naman ng kolonyalismong Amerikano, lalong tumingkad ang mga paniniwala sa busaw/tarabusaw na sumasapi sa katawan ng mga Bukidnon Manobo na nagtutulak sa kanila upang gumawa ng karahasan na pinaigting ng mga mananaliksik tulad ng antropologong si Fay Cooper Cole (1913) sa kaniyang pag-aaral sa kultura ng mga Bukidnon. Kung pagbabatayan naman ang lokal na kasaysayan sa Kabisayaan, maaaring matunton ang sinasabing demonisasyon sa pagsapi ng surog sa mga babaylan/ma-aram at ang tila kahalintulad nitong pagbabagong anyo ng aswang sa nangyaring paghihimagsik laban sa mga Amerikano noong 1899 hanggang 1907 na pinangunahan ng mga babaylan (Aguilar, 1997). Sang-ayon sa kasaysayan ng Negros, naging espasyo ng paghihimagsik ang kapuluan ng Visayas sa mga huling taon ng kolonyalismong Espanyol patungo sa nagsisimulang kolonyalismo ng mga Amerikano (Aguilar, 1997). Naging mukha ng himagsik si Dionisio Sigobela, na mas kilala rin sa tawag na Papa Isio o ang "maayo nga lalaki," katuwang ang maraming bilang ng mga babaylan na may tangantangang armas at anting-anting na lumaban sa mga Amerikano (Aguilar, 1997). Mahihiwatigan sa bahaging ito ang pagdidigmaan ng kinagisnang paniniwala at ang paniniwala ng mga mananakop, animo'y nagsasabong ang dalawang panig na sa huli'y magtatanghal sa isa bilang taal at dalisay habang sa isa naman bilang marahas at masama.

Kung susumahin, lumilitaw ang mga ganitong talastasang binabanggit hinggil sa nililikhang larawan ng kinagisnan at bagong paniniwala sa imahen ng mga aswang sa pelikulang katatakutan. Bagama't hindi lamang babae ang 
aswang sa "Lihim ng San Joaquin" ng SRR 2K5 (Monteverde, Monteverde, \& Somes, 2005) kundi isang lupon na binubuo ng mga lalaki at babae, mapapansin na katulad pa rin ng sa Yanggaw (Arguelles, Montelibano, Montelibano, \& Somes, 2008) at Corazon: Ang Unang Aswang (Calmerin, Kintanar, Samson-Martinez, \& Somes, 2012), nakatatakot at nakakikilabot ang transpormasyon nito mula sa pagiging tao patungo sa pagiging halimaw. Nagiging prominente lamang ang paglalarawan sa aswang sa mga pelikula ni Somes dahil sa seksuwalisasyong ipinapataw dito-isang babaeng makasalanan, tagalabas, at yumayanig sa kaayusan ng lipunan at bansa. Kung ang mga babaylan/ma-aram ay walang kinikilalang kasarian, mapapansin ang ipinapataw na kasarian sa aswang ng mga pelikulang katatakutan: isang babaeng nagpapalit ng anyo patungong halimaw.

Kung susuriin, tila ironiko at paradohikal ang pagtingin sa aswang bilang babae lalo na't ang babae ang siyang hinaharaya sa pambansang imahinasyon bilang larawan ng bansa: si "Inang Bayan." Sa saray ng makalalaking naratolohiya sa kasaysayan, ang bayan ay Babae-Inang Bayan-na kinakailangang igalang, sambahin, at protektahan, sa isang banda, ngunit kaakibat din nito ang pagiging biktima ng pananamantala, panggagahasa, at panunupil, sa kabilang banda. Mapanganib ang pagbibigay seksuwalidad sa Bayan bilang babae lalo na't nakabatay ito sa imahen ng dinadahas na lunan na kinakailangang isalba upang makamit muli ang pagiging malaya, wagas, at lantay.

Kung titingnan naman ang pangalawang diskursong mahuhugot sa tatlong pelikula tungkol sa aswang, malalantad ang diskurso hinggil sa anyo ng katatakutan at espasyo na umiinog sa konstelasyon ng sistema ng moralidad, relihiyon, at asyenda na malimit na kumikiling sa pagsasamantala at panunupil. Maliwanag sa "Lihim ng San Joaquin" (Monteverde, Monteverde, \& Somes, 2005) at Yanggaw (Arguelles, Montelibano, Montelibano, \& Somes, 2008) ang mga lugar na pinangyarihan ng naratibo, ang una'y sa isang liblib at tila kinalimutang baryo sa Luzon habang ang huli naman, batay na rin sa gawi at wika ng mga karakter, ay nakalunan sa isang ibinukod na komunidad sa probinsiya ng Negros Occidental sa Visayas. Ang Corazon: Ang Unang Aswang (Calmerin, Kintanar, Samson-Martinez, \& Somes, 2012) naman ay hindi naghayag ng lantarang lunan ng naratibo ngunit lumilitaw pa rin na nangyari ito sa isang malayong asyenda na siyang pugad ng panunupil at pananamantala.

Sa daloy ng naratibo ng "Lihim ng San Joaquin" (Monetverde, Monteverde, \& Somes, 2005), hindi maipagkakailang inspirasyon nito ang naunang matagumpay na episodyong "Aswang" mula sa Shake, Rattle, and Roll 2 (1990)—nilikha ng Ilonggo ring direktor na si Peque Gallaga na may malaking impluwensiya sa sining ni Somes. Sa "Lihim ng San Joaquin," 
tinatampok ng kuwento ang liblib na baryo ng San Joaquin na nakahiwalay sa mga karatig nitong lugar. Litaw na litaw ang pagiging rural ng San Joaquin, tila nasa gitna ito ng kagubatan, malayo sa siyudad, at nag-iiba ang itsura sa tuwing sasapit ang gabi. Kalakip ng tila kinalimutan sa laylayan na baryo ng San Joaquin ang taglay nitong lihim - pinamumugaran at pinamamalagian ito ng mga aswang. Sa kuwento, isang mortal na tao na ginawang alipin sa baryo ang magpapatunay at magsasalaysay sa kasaysayan at pinagmulan ng mga aswang:

(Alipin) Ang San Joaquin ay ang huling himpilan ng mga aswang na galing pa sa Visayas at Mindanao, dito na sila tumira at mamamatay. (Monteverde, Monteverde, \& Somes, 2005)

Sapin-sapin ang nagtatagisang elemento sa pahayag ng alipin ukol sa pag-iral at pinanggalingan ng mga aswang. Una, ipinapalagay na ang mga aswang ay nagmula sa Visayas at Mindanaw at lumipat lamang sa Luzon upang doon itayo ang kanilang huling himpilan. Kung susuriin, lumilitaw dito ang diskurso ng espasyo sa Pilipinas bilang isang hinaharayang pamayanan (imagined community) kung saan magkakahiwalay at watak-watak man ang mga lunan, pinagkakabit-kabit at pinagdudugtong-dugtong pa rin ito ng iisang bansa at diwa. Sa pagpapakahulugan ng pelikula ukol sa pagtatayo ng kanilang huling himpilan sa Luzon matapos sa Visayas at Mindanaw, nililikha ang muli't muling paghahati sa sentro at mga bayan sa labas nitoiyong mga iniwan sa laylayan ng bansa. Sa diskurso ng kolonyalismo sa bansa, bunga ng kahirapang mapasok ng mga dayuhang Espanyol ang ilang lugar sa Visayas at Mindanaw, sa Maynila sa Luzon itinayo ang iba't ibang himpilan na kalaunan ay magiging sentro ng lahat ng institusyon sa bansa. Sa ganitong konteksto, tuluyang inihihiwalay at nagiging Iba (Other) ang mga bayan sa labas ng Maynila.

Pangalawa, kung sinasabing ang mga aswang ay nagmula sa mga liblib na lugar sa Visayas at Mindanaw, lumilikha ng diskursibong kahulugan ang paglalarawan na ito sa espasyo ng rehiyon. Tila nakukulong na naman sa pagiging primitibo, walang sibilisasyon, at nakatatakot ang imahen ng mga probinsiya sa rehiyon. Sa ganitong konteksto, nagiging lehitimo ang pananakop sa malalayong lalawigan at probinsiya sa pagnanasang mabago ang anyo nito patungong moderno at urbanisadong siyudad kahit na ang totoo'y magkapantay lamang ang estado nito at ng sinasabing mauunlad na siyudad sa sentro (Chakrabarty, 2000; Fabian, 1983). Dagdag pa rito, mapaniil din ang pagsasalin ng naratibo at anyo nitong katatakutan, ang mga ganitong larawan ay nagbubunga ng higit na problematiko at mapanghating 
dikotomiya sa pagitan ng "lungsod at nayon, ng kabataan at katandaan, ng luma at bago" (Guieb, 2009, pp. 98-99). Dagdag pa ni Guieb:

Nitong mga huling taon ay kapansin-pansin ang
pagbibigay-tuon sa mga tinaguriang "modernong"
kabataan na "nagbabakasyon" sa probinsya upang
sinasadya o di-sinasadyang harapin ang makaluma subalit
kontemporaneong mundo ng mga aswang at maligno, ng
mga espirito at totoong tao, ng hiwaga at mga lantad na
realidad,... Sa mga sineng ito, ang kababalaghan ay idinidikit
sa mga liblib na lugar, at ang mga lugar na ito ay mga lunan
ng adventure o "happening" ng mga sinasabing makabagong
kabataan. Mahalagang pag-aralan ang ginagawang makitid
at simplistikong paghahati ng moderno at tradisyonal, ng
luma at bago. (p. 99)

Kung susumahin, reduktibo ang pagpapalagay na ang mga malalayo at liblib na probinsiya, iyong nakasandig at may bakas ng katutubong komunidad, ang siyang pinamumugaran ng mga aswang at iba pang halimaw habang ang mga siyudad naman ang lunan kung saan tiyak ang kaligtasan. Sa ganitong pagbasa, umaalingawngaw pa rin ang proyektong reduccion sa panahon ng Espanyol kung kailan inilipat ang kalat-kalat na mga tao mula sa bukirin at bundok patungo sa mga pueblo, ang lugar na maaabot sila ng tunog ng kampana ng simbahan (bajo de las campanas), ibig sabihin, maaabot ng kapangyarihan ng mga dayuhang Espanyol. Naroon sa gitna ng pueblo ang plaza, kung saan itinatanghal ang mga metriko romanse, moro-moro, at loa, habang nakapalibot naman dito ang simbahan, ospital, munisipyo, paaralan, at iba pang institusyon na magpapatunay sa pagiging moderno, sibilisado, at progresibo ng lugar (Santos, 1994). Pangunahing layunin ng reduccion ang tipunin ang lahat ng katutubo upang isang buong kolektibo itong masakop ng bagong relihiyon at pamahalaan na bitbit ng mga Espanyol (Rafael, 1988). Sa ganitong kaayusan, pinagmumukhang ang mga liblib na baryo sa "rehiyon" ay mapanganib at marahas habang ang mga siyudad sa "sentro" ang lunan ng kadalisayan at kaunlaran. Ngunit kung titingnan naman ang pagtingin ng mga komunidad na nakasandig at may bakás ng katutubong komunidad, mapapansin na iba rin ang pagpapakahulugan nito sa siyudad. Hindi maipagkakaila ang pagtingin ng katutubong komunidad sa siyudad bilang marahas, malayo, at espasyong dapat iwasan. Tinatanaw din ang siyudad bilang "Layasan" kung saan dinadala ang mga traydor at mahihina sa bawat komunidad.

Samantala, mapapansin din na ang pangalan ng liblib na baryo sa kuwento ay San Joaquin, tumutukoy sa pangalan ng isang santo. Sa 
paniniwalang Katoliko, sinasabing si San Joaquin ang asawa ni Santa Anamga magulang ni Birheng Maria. Itinuturing din si San Joaquin bilang santong patron ng mga mag-asawa (Brownrigg, 2001). Kung susundan ang ganitong pagbasa, ang baryo ng San Joaquin na inilalarawan sa kuwento ay mayroong malaking impluwensiya ng kulturang Hispaniko. Kung gayon, may ironiya sa San Joaquin bilang liblib at malayong pook, at tulad ng mga naunang pueblo na nilikha ng mga Espanyol, malapit ito sa lahat ng mga institusyon. Idagdag pa ang sinasabing lihim ng pook na nangangahulugang may itinatago ito. Maikakabit sa diskursong ito ang pook sa awiting-bayan na "Doon Po Sa Amin" na mayroon ding inililihim. Kung susundan ang unang dalawang bahagi ng awit (Almario, 2015):

Doon po sa amin

Sa bayan ng San Roque

May nagkatuwaang

Apat na pulubi

Nagsayaw ang pilay,

Nakinig ang bingi,

Nanood ang bulag,

Umawit ang Pipi. (p. 42)

Tulad ng San Joaquin, mapapansing may impluwensiya rin ng kulturang Hispaniko ang bayan ng San Roque sa awit. Maaaring ipagpalagay na hindi nalalayo ang binabanggit na San Roque sa mga pueblo na naging resulta ng reduccion. Ngunit mapapansin din sa awit ang apat na "pulubi," ibig sabihin ay naghihirap sa buhay dahil sa kawalan ng matinong trabaho at tirahan, na may kaniya-kaniyang kapansanan. Ngunit pansinin na may kalakip ding parikala sa bawat kapansanan ng mga pulubi: ang pilay ay maaaring magsayaw; ang bingi ay maaaring makadinig; ang bulag ay maaaring makakita at makapanood; at ang pipi ay maaaring umawit. Sa diskursibong paglikha ng kahulugan, maaaring ang konteksto ng awitin ay nasa panahon ng kolonyalismong Espanyol. Sa panahong ito, laganap ang pagkalap para sa mga binata na maaaring maging miyembro ng kawal ng hukbong Espanyol; tanging ang mga binatang may kapansanan lamang ang maaaring makaligtas sa pangangalap na ito. Marahil, dahil ang lunan sa awiting-bayan ay sa loob ng pueblo na abot ng tunog ng kampana (bajo de las campanas), kinakailangang magpanggap ng mga binata na may kapansanan sila kahit na ang totoo'y wala naman.

Ang lihim ng bayan ng San Roque ay maaaring kadugtong din ng lihim ng San Joaquin sa naratibo ng pelikula. Ang lihim ng dalawang pook ay nagsasanga at nagkakaiba, ang isa'y may inililihim upang isalba ang 
mamamayan nito sa mapang-api at mapang-abusong sistema ng pagiging kawal, habang ang isa nama'y inililihim ang pagiging "aswang" ng mga mamamayan nito. Inosente ang mga "pulubi" na nagpapanggap na may kapansanan dahil sa takot nilang maging miyembro ng kawal habang masaya naman sa pag-imbita ang mga aswang sa mga bagong dayo sa kanilang pook na maaari nilang kainin at pagsalo-saluhan.

Hindi rin maitatanggi ang talinghaga ng mitolohikong espasyo ng San Joaquin bilang isang mahalagang bayan sa kasaysayan ng Iloilo. Marahil, hindi kaila sa imahinasyon ni Somes bilang Ilonggo ang papel na ginampanan ng San Joaquin sa prekolonyal na kasaysayan sa bansa. Kung pagbabatayan ang Maragtas, sa Ilog Siwaragan (Suagan o Sugan) sa San Joaquin unang dumaong ang 10 datu mula Borneo na tumakas sa hindi maayos na pamamahala ni Makatunao. Sa paglalakbay ng mga datu at kanilang kasama, mapapadpad sila sa Panay kung saan sila magtatayo ng kanilang aangkining komunidad noong ika-12 dantaon (Bautista, 2017). Kung babalikan, tanyag na espasyo nang matatawag ang San Joaquin bago pa man dumating ang mga Espanyol lalo na't naging sentrong lunan ito ng kalakalan at matatag na muog na tumututol sa pagpasok ng mga Muslim. Sa ganang ito, makikita ang kapuri-puring papel na ginampanan ng San Joaquin sa prekolonyal at kolonyal na kasaysayan ng Iloilo at bansa ngunit sa pelikula ni Somes, naging isang lunan lamang ito ng mga aswang na pumapatay ng tao sa ngalan nang pagpatay.

Samantala, hindi rin naman naiiba ang kuwadro ng pagtingin sa pook ng "Lihim ng San Joaquin" (Monteverde, Monteverde, \& Somes, 2005) sa naratibo ng Yanggaw (Arguelles, Montelibano, Montelibano, \& Somes, 2008). Tila nagkakatulad sa pagiging malayo, mapanglaw, at atrasado ang imahen ng dalawang pook. Kung tuwirang nakalunan sa malayong komunidad sa isang rehiyon sa Panay ang Yanggaw, mahihiwatigan ang paglalarawan dito bilang pugad ng mga nakatatakot na pamahiin, lumang paniniwala, at hindi maipaliwanag na mga gawi at kilos. Sa naratibo, hindi malinaw ang sanhi ng pagiging "aswang" ni Amor. Sinasabing ito ay "yanggaw," ibig sabihin ay nahawahan ng pagiging "aswang" gamit ang laway; o kaya naman, ito ay isang sakit na hindi maipaliwanag, tulad ng sinabi ng albularyong sinubukang manggamot dito. Sa puntong ito, lumilikha ng sapin-saping diskurso ang naratibo ng Yanggaw: una, tinatanaw pa rin ang mga liblib na baryo bilang lunan kung saan nagtatagpo ang kawalang kalinisan, kawalan ng kaunlaran, at kawalan ng tampulan sa kalusugan na nagbubunga ng sakit na nakahahawa, dahilan sa pangangailangang sumailalim ito sa "proseso ng sibilisasyon" (civilizing process) (Anderson, 2007); pangalawa, maaaring iugnay sa naratibo ng pelikula ang sakit ng Dystonia Parkisonism o tinatawag ding "lubag" (pilipit) na laganap sa Panay_karamdaman sa kalamnan ng 
katawan na nagbubunga ng pamimilipit at pamamaluktot ng iba't ibang bahagi ng kalamnan ng tao hanggang sa ang itsura nito'y maging kawangis na ng kinagisnang imahen ng aswang (Baes, 2011); at pangatlo, maaari ding ipagpalagay na isang talinghaga ang sakit na tinutukoy sa Yanggaw (Arguelles, Montelibano, Montelibano, \& Somes, 2008), marahil, ito ang sakit ng pagkataong Filipino na hatid ng mapaminsalang kultura tulad ng taal na pagbibigay-pugay at pagmamahal sa pamilya kahit na kapalit nito ay ang pagiging mapamuksa sa iba pang tao at nasasakupan.

Mauugnay ang realidad ng aswang sa Yanggaw (Arguelles, Montelibano, Montelibano, \& Somes, 2008) sa binabanggit ni Bliss Cua Lim (2011) hinggil sa pag-iral ng aswang at kaluluwa hindi lamang sa iisang yugto ng kasaysayan kundi ito'y nasa noon, narito, at naroon. Bumabalik-balik sa bawat panahon, dumadalaw, nagpaparamdam, at nagbabalik ang aswang at kaluluwa. Mahalaga ang puntong ito ni Lim lalo na sa diskurso ng postkolonyalismo dahil kung titingnan lamang ang panahon sa dalumat ng mekanikal na orasan at kalendaryo, nagkakaroon ng iisang naratibo ang pagpapakahulugan sa mga kaalaman na nakabatay lamang sa modernong panahon. Sa naratibo ng Yanggaw (Arguelles, Montelibano, Montelibano, \& Somes, 2008), hindi lamang maaaring tingnan sa pananaw ng atrasado at primitibong panahon ang pag-iral ng aswang sapagkat umiiral din ito sa kasalukuyang panahon kung kailan dinadambana ang agham, siyensiya, at medisina. Kung titingnan ang panahon sa pelikula, nagkasakit si Amor ng hindi mapangalanang sakit sa kasalukuyang panahon. Sa isang eksena sa pelikula, dinala si Amor sa albularyo ngunit wala rin itong nagawa. Matapos ito, dinala siya sa klinika ngunit doo'y inabutan lamang siya ng isang health worker ng antibiotic. Sapin-saping pagpapakahulugan ang maaaring ipatawa sa eksenang iyon tulad ng hindi gaanong pagbibigay tuon at interes ng gobyerno sa batayang panlipunan serbisyo sa malalayo at liblib na lugar sa rehiyon at ang hindi pa malirip ngunit bukas sa pagtuklas na lunas sa sakit o impeksiyon ni Amor. Sa antas ng panahunan, maipagpapalagay na hindi pa natutuklasan ng medisina ang gamot na magbibigay-lunas kay Amor ngunit buntis ang mga posibilidad ng panahon sa pag-unlad at pagkakatuklas dito. Patunay sa talastasan ng panahunan ng pangnagdaan, pangkasalukuyan, at panghinaharap.

Kakabit naman ng mga lunan sa pelikulang "Lihim ng San Joaquin" mula sa Shake, Rattle, and Roll 2k5 (Monteverde, Monteverde, \& Somes, 2005) at Yanggaw (Arguelles, Montelibano, Montelibano, \& Somes, 2008) ang espasyo ng naratibo ng Corazon: Ang Unang Aswang (Skylight Films \& Richard Somes, 2012). Prominente ang paglililok ng Corazon sa pook na pinangyarihan ng kuwento-nakapailalim ito sa sistema ng asyenda sa panahon kung kailan katatapos pa lamang ng Ikalawang Digmaang 
Pandaigdig. Ngunit, kung babalikan ang naratibo ng pelikula, tila naging artipisyal na kasangkapan lamang ang espasyo at panahon na binabanggit. Tila nawawalan ng bigat ang dulot ng espasyo at panahon sa naratibo lalo na't mahalagang lunan at pitak ang mga ito sa kasaysayan ng bansa. Hindi maihihiwalay ang imahinasyon ni Somes, bilang isang Ilonggo na direktor ng pelikula, sa isang komposong Panayanon na may pamagat na "Basilio." Binabanggit sa huling saknong ng komposo (Cruz-Lucero \& Lumbera, 2001):

Sang tatlo na yadto ka adlaw

may sugilanon nagalayaw

nagasinggit sila ay Dios ko ay abaw

si Basilio daw bag-ong yanggaw. (p. 452)

[Matapos ang tatlong gabi

kumalat na ang balita

at ang lahat ay nagsigawan, Diyos ko

si Basilio ay naging isa nang ganap na aswang.]

Kung susuriin ang huling bahagi ng komposo, masasabing may politikal, pang-ekonomiya, at panlipunang komentaryo ito na nagtatampok sa pananamantala at inhustisya na bunga ng sistema ng asyenda at digmaan. Tampok sa komposo ang pagpatay ng isang tatay na ang pangalan ay Basilio sa kaniyang anak na babae na si Pascuala, at ang lahat ng ito ay dahil sa gutom. Masasabing malaki ang ambag ng dalawang pangyayaring ito sa realidad kung bakit marami ang nasasadlak sa gutom na nagtutulak sa mga indibidwal upang kumain ng kaniyang kapuwa. Patunay din ang pangyayaring ito sa lugmok na kalagayan ng mga rehiyon na tila kinaliligtaan ng mga institusyon mula sa bansa na sana'y naghahatid sa kanila ng mga pangunahing pangangailangan upang mabuhay. Kung pagbabatayan ang Corazon (Calmerin, Kintanar, Samson-Martinez, \& Somes, 2012) hindi naiiba ang sinapit nina Basilio at Corazon na pagpatay sa kani-kanilang sariling anak: ang una'y dahil sa gutom habang ang pangalawa'y dahil sa galit, poot, at kawalan ng pananalig. Bagama't malay ang komposo sa panlipunan, pangkultural, pampolitika, at pangkasaysayang danas, tila nakaligtaan naman ng Corazon ang mga ito lalo na't malabo at hindi maaninag ang mga ganitong komentaryo.

\section{Tama(w)o}

Sa imahinasyon ng mga Ilonggo, may paniniwala tungkol sa mga "tamao" o "tamawo" na tumutukoy sa mga mahiwagang nilalang na kalimitang naninirahan sa mga punongkahoy. Kung pagbabatayan ang etnograpikong 
datos na nakalap ni Alicia Magos (1992) sa komunidad sa Antique, mahihinuha ang paniniwala ng mga tao rito hinggil sa pag-iral ng mga tama(w)o na namamalagi sa isa sa mga suson sa kosmolohikong daigdig sa Panay. May paniniwalang nananahan ang mga tama(w)o sa paligid lamang na hindi hiwalay at nalalayo sa daigdig ng tao. Inilalarawan ang mga tama(w) o bilang mga nilalang na nagtataglay ng magandang mukha at puting kulay ng balat. Bagama't nagkakaiba-iba sa paglalarawan at itsura, nagkakatulad naman ang mga tala ukol sa karanasan sa tama(w)o, murokpok, kama-kama, bawa, burulakaw, at kapri. Hinaharaya ang mga nilalang na ito na lumilibot sa kaligiran ng Bundok Kanlaon at Panay. Sa pagkakakilanlan sa tama(w) o, nag-iiba-iba ang katawagan sa kanila batay sa kanilang mga katangian, nariyan ang bumalabag, liktin-laktud, manupongtupong, manla-aw-la-aw, manilagnilag, at mambukay o kalambukay (Magos, 1992, pp. 51-59).

Sa pagtataya naman ni Rosario Cruz-Lucero (2007), ang mga tama(w) o ay ang katumbas ng salitang diwata sa wikang Hiligaynon. Dagdag pa niya, ang pagkakahati sa mga nilalang batay sa lingguwistikong antas ay isang dambuhalang impluwensiyang dumating sa prekolonyal na daigdig sa Pilipinas sa pagsisimula ng kolonyalismo sa panahon ng mga Espanyol. Nilapatan ng pagpapakahulugang pambabae ang huling titik ng mga salitang nagtatapos sa "a" at panlalaki naman ang "o" (p. 26). Maaaring ipagpalagay na ang tama(w)o ay hindi kaiba sa mga "tanod" para sa mga Tagalog—mga nilalang na naatasang magbantay sa iba-ibang bahagi ng kalikasan tulad ng bundok, dagat, ilog, sapa, at matatandang bato. At kung hinaharaya ang mga tanod at tama(w)o na ito bilang malalayang nilalang sa prekolonyal na yugto sa kasaysayan, malilimitahan at mapipinid ang katangian nito sa nakamamanhid na pagkukulong sa lingguwistikong batayan ng kasarian sa bisperas ng kolonyalismong Espanyol.

Sa isa sa mga episodyo ng sugidanon (epiko) ng mga Panay Bukidnon na Labaw Donggon, binabanggit ang nilalang ng isang makapangyarihang tama(w)o na nagpahina sa kapangyarihan nang magiting na si Labaw Donggon-si Saragnayan (Castro, Antonio, Melendez-Cruz, Mariano, \& Makasiar-Puno, 1983):

Buyung Labaw Donggon,

Imprisoned he might be by Saragnayan

Underneath his home.

Or else swallowed he might have been,

For a tamao is Saragnayan,

A notorious devourer of men. (akin ang diin) (p. 151)

Mahalagang pansinin ang paggamit ng katawagang tama(w)o sa siniping bahagi ng isinaling bersiyon ng Labaw Donggon lalo na't sa orihinal na 
bersiyon ay aswang at tagubalbal ang mga ginamit na salita. Kung papansinin naman ang salin ng orihinal na bersiyon sa Tagalog, mangkukulam at kumakain ng tao ang siyang mga ginamit na paglalarawan. Sa puntong ito, tila nagkakaroon ng mabuway na pagpapakahulugan at hindi malinaw na pagkakaiba sa nilalang ng tama(w)o, aswang, tagubalbal, ${ }^{4}$ at mangkukulam.

Marahil, hindi rin naman nalalayo ang mga tanod at tama(w)o sa mga nilalang na tinatawag na engkanto. Maaaring ipagpalagay nga lamang na hindi taal ang salita sa kultura at lipunang Filipino. Marahil, maaari ding wala sa "katutubong" imahinasyong Filipino ang dalumat nito dahil masasabing nagmula ito sa wika at kulturang Hispaniko. Sa pagtataya ni Francisco Demetrio (1969), ang engkanto ay nagmula sa salitang Espanyol na encantado. Mahuhugot mula sa salitang encantado ang pandiwang encantar na nangangahulugang "pagkabighani, pagkahalina, at pagkaakit." Sa pagtanaw ni Demetrio, hindi bago ang dalumat ng engkanto sa kulturang Filipino bagama't dayuhan lamang ang ibininyag niyang katawagan. Sa manuskritong Povedano noong 1578 ay tinatawag na raw itong "tumao," "tiaw" naman para sa mga taga-Cagayan de Oro, Gingoog City, at Misamis Oriental, "meno" naman sa siyudad ngIligan, "panulay" sa Siquijor, "tagbanua" sa Talakag, Bukidnon, at "dili ingon nato" para sa iba pang mga Bisaya. Dagdag pa ni Demetrio, ang mga engkanto ay kalimitan daw matatagpuan at namamalagi sa kanilang daigdig na nakapaloob sa malalaking bato, sa mga siwang sa ilalim ng lupa, o kaya'y sa puno ng balete (p. 588). Bagama't nagsasanga-sanga at nagkakaugnay-ugnay ang mga pagpapakahulugan, hindi nagiging malinaw kung nararapat nga bang tawaging engkanto ang mga tumao, tiaw, meno, panulay, tagbanua, at dili ingon nato ${ }^{5}$ dahil ang bawat katawagang ito, mula sa kaniya-kaniyang pinanggalingan, at may mga kakabit na karanasan na maaaring iba sa pagpapakahulugang "pagkabighani, pagkahalina, at pagkaakit." Mahalagang sipatin na tila nagbabanggaan sa espekulasyong ito ni Demetrio ang katutubong sistema ng paniniwala at relihiyong Kristiyanismo.

Sa "Tamawo" mula sa SRR 13 (Monteverde, Monteverde, \& Somes, 2011), tampok ang naratibo ukol sa paglipat ng mga karakter mula sa siyudad ng Maynila patungo sa liblib na kagubatan sa isang malayong rehiyon. Isang nagsisimulang pamilya ang piniling mamuhay sa gitna ng isang asyenda na pinaghaharian ng ganid na panginoong may lupa. Ngunit, sa hindi inaasahang pagkakataon, makakakita ang pamilya ng isang makintab at malaking kristal na tila itlog na naglalaman ng sanggol na tama(w)o. Hati ang pamilya tungkol sa kanilang gagawin sa kristal. Ang tatay ay naniniwalang ito ang magsasalba sa kanilang kahirapan habang ang nanay at ang anak nitong batang lalaki ay naniniwalang kinakailangan itong ibalik sa mga tama(w)o. Sa huli, bunga ng pag-aaway ng pamilya kung 
ano ang dapat gawin sa kristal na itlog, mababasag ito at magiging dahilan ng pagkamatay ng sanggol na tama(w)o. Bilang ganti, kinuha ng grupo ng mga tama(w)o ang batang lalaki upang siyang maging kapalit ng kanilang namatay na sanggol.

Sa episodyong ito ni Somes, tila naiiba ang paglalarawan sa tama(w)o kung pagbabatayan ang mga nauna nang sinuring pagpapakahulugan. Sa isang tagpo sa "Tamawo," binabanggit ng karakter ng albularyo na si Epang kung papaano nila tinatanaw ang mga nilalang:

[Ang mga tamawo] ang mga nilalang na tinanggihan ng langit at iniluwa ng lupa. Mga halong maligno at diwata. Noong araw, ang sabi sa akin ng lolo ko, madalas daw na manguha ng mga tao ang mga tamawo, lalo na ng mga bata. (Monteverde, Monteverde, \& Somes, 2011)

Mula sa pagpapakahulugang ito, mapapansin ang ikinakabit na imahen sa tama(w)o na tila sumusunod sa kolonyal na paniniwalang nakasandig sa Hudeo-Kristiyano: pinagkaitan ng pagkalinga mula sa langit (kalangitan) at hindi rin naman tinanggap sa lupa (impiyerno). Ibig sabihin ay nasa pagitan lamang sila ng ibabaw at ilalim at doon naghahasik ng lagim at kasamaan. Sa puntong ito, nalusaw ang naunang pagtanaw sa mga tamawo bilang tanod na nagbabantay sa mga bahagi ng kalikasan sa daigdig. Maaari din namang ipagpalagay na tila bunga ang ganitong espekulasyon ng heograpikong disenyo ng mga komunidad kung saan ang mga paniniwala ng mga nasa laylayan ay pinagmumukhang atrasado at walang pag-abante.

Samantala, kung babalikan ang naratibo ng episodyong "Tamawo" (Monteverde, Monteverde, \& Somes, 2011), hagdan-hagdan din ang diskursong nakapaloob hinggil sa nilalang ng tama(w)o, sistema ng asyenda, at diyalektika ng "rehiyon" at "bansa." Sa kuwento, naghihiganti ang mga tamawo dahil sa pagnanakaw sa kristal na itlog na naglalaman ng kanilang sanggol. Mahalagang sipatin sa naratibo ng pelikula ang pinangyarihang gubat na nakapaloob bilang bahagi ng rantso o asyenda ng isang mayamang negosyante. Kung babalikan ang naunang pagpapakahulugan sa mga tama(w) o bilang tanod at taga-bantay ng mga bahagi ng kalikasan, tila lumilikha ng pagkalito at hindi pagtutugma ang inihahayag ng pelikula sa kung sino nga ba ang nagmamay-ari sa gubat na bahagi ng asyenda sa isang banda, at tinitirahan naman ng mga tama(w)o, sa kabilang banda. Umaalingawngaw pa rin sa puntong ito ang sistemang encomienda at pueblo na pamana ng koloniyalismong Espanyol. Kung ang gubat ay hinaharaya bilang bahagi ng kalikasan na tinitirahan ng iba't ibang uri ng nilalang, malaking pagbabago naman ang ipinamana ng pagtatayo ng mga asyenda sa kapatagan at maging sa kabundukan. Maiuugnay ang pangyayari sa talastasan ng gahum ng 
katutubong sistema ng paniniwala (indigenous belief system) at kulturang bitbit ng mga mananakop na nakapaloob sa lunan ng asyenda. Litaw na litaw sa sistemang ito ang nagtatagisang kultural, panlipunan, pampolitika, at panrelihiyong paniniwala ng mga asyendero - ang siyang may hawak ng kapangyarihan na karaniwa'y mananakop o kanilang mga inapo-at mga trabahador at magbubukid - na sila namang gumagawa ng lahat ng mahihirap na gawain sa loob ng asyenda na kalimita'y ang mga sinasakop. Sa ganitong ugnayan, iniluluwal ang kayariang sinasalikop ng prekolonyal, kolonyal, at postkolonyal na mga daigdig (Aguilar, 1998). Mababakás din naman sa "Tamawo" (Monteverde, Monteverde, \& Somes, 2011) ang ganitong ugnayan lalo na't piyudal ang sistema ng may-ari ng asyenda sa kaniyang nasasakupan tulad ng pagtawag sa kanila ng mga magsasaka bilang "amo."

Ang diskurso ng "Tamawo" ni Somes (Monteverde, Monteverde, \& Somes, 2011) at ang kakabit nitong pahayag tungkol sa sistema ng asyenda ay hindi hiwalay sa danas na binabanggit ni Filomeno Aguilar sa librong Clash of Spirits: The History of Power and Sugar Planter Hegemony on a Visayan Island (1998) na nagtatampok sa pagtatagisan ng kapangyarihan ng nagbabanggaang prekolonyal at kolonyal na mga mundo sa kasaysayan at kultura ng Negros. Tingnan, halimbawa, ang tagisan at ugnayan ng babaylan at mga espiritu ${ }^{6}$ sa prekolonyal na yugto; ang pagsasanib ng babaylan at mga espiritu katunggali ang gahum ng mga prayle; at ang pagsasakatutubo ng paniniwalang Katoliko at umuusbong na mga mestisong Protestante laban sa humihinang sistema ng piyudalismo patungo sa umuusbong na kapitalismong mason. Kaugnay ng pagsusuring ito ni Aguilar ang lunan ng asyenda na prominenteng tagpuan sa episodyong "Tamawo."

Kung sa "Tamawo," (Monteverde, Monteverde, \& Somes, 2011) ipinapakita ang laganap na kaapihan na nagaganap sa loob ng asyenda sa pagitan ng mga manggagawa rito at panginoong may-ari ng lupa-dahilan upang gumawa ng masama ang manggagawa tulad ng pagnanakaw ng kristal na itlog ng tama(w)o-hindi rin naman hiwalay ang realidad na ito sa nangyayari sa iba-ibang "asyenda" sa iba't ibang rehiyon sa bansa. Sa pananaw ni Aguilar (1998), ang asyenda sa nag-iiba-ibang panahon sa bansa ay tagpuan ng dalawang magkaiba at nag-uumpugang mga puwersa. Halimbawa, tunggalian sa pagitan ng mga espiritu, ang isa ay nagmumula sa paniniwala ng mga katutubo habang ang isa naman ay mula sa paniniwalang bitbit ng mga dayuhang Espanyol. Tinunton ni Aguilar ang sinasabing pagkakaiba ng mga espiritu na ito. Sa isang banda, ang banal na espiritu sa Kristiyanismo na kaanib sa tatlong persona habang sa kabilang banda, ang prekolonyal at katutubong sistema ng paniniwala na nagtatanghal sa tinatawag na "dungan"-isang enerhiya, o marahil, entidad, kalapit ng 
kaluluwa, na may sariling kakayahang mamalagi sa katawan ng tao. Ang pagkakaroon ng malakas na dungan ang tradisyonal na pagpapakahulugan sa pagiging tuso, matalino, at kakayahang mapagtagumpayan ang lahat ng kontradiksiyong susuungin. Mahalagang punto ang dungan na ito sa binabanggit ni Aguilar sa dalumat ng "sabong" na makikita sa relasyon ng kapangyarihan na nakapaloob sa sistema sa loob ng asyenda sa Kabisayaan.

Ang sabong ay isang tradisyonal na laro na ang manlalaro ay kinakailangang tumaya kung sino sa dalawang nagtatagisang manok ang sa tingin niya'y mananalo. Sa pangyayaring ito inilalarawan ni Aguilar ang sitwasyon ng mga katutubo na naiipit sa dalawang nagbabanggaang kultura, paniniwala, at kapangyarihan. Ang katutubo, dagdag ni Aguilar, ay kinakailangang tumaya sa larong binabanggit. Sa ganang ito, may mga piniling pumanig at tumaya sa kulturang Hispaniko dahil ito ay nangangahulugan din ng kapangyarihan at proteksiyon mula sa mga fraile lalong-lalo na sa kanilang lupang tinataniman at sinasaka. Ngunit, mayroon din namang mga mas piniling tumaya at labanan ang nanghihimasok na dayuhang kultura at kapangyarihan.

Sa kasaysayan ng sistemang asyenda sa Negros, may panahon noong 1860 na naging masidhi ang pangangailangan para sa mga magsasaka sa iba't ibang asyenda (Aguilar, 1998). Mahalaga ang yugto na ito dahil ginamit itong daluyan ng mga magsasaka at manggagawa upang baligtarin ang hugis na may inaapi at nang-aapi. Ani ni Aguilar (1998), sa puntong ito, naging subersibo ang pagtaya ng mga katutubo sa kinapapalooban nilang sabong ng dalawang magkaibang kultura. Litaw na litaw sa pag-aaral ni Aguilar na hindi lamang tuwirang pagtaya sa pagpapasakop sa gahum ng dayuhang kultura ang naging tugon ng katutubo. Masasabing isang mahalagang punto ang ginawang pagtaya ng mga katutubong magsasaka at manggagawa sa paglaban sa naghaharing institusyon at sistema ng asyenda.

Kung babalikan ang naratibo ng episodyong "Tamawo" (Monteverde, Monteverde, \& Somes, 2011), makikita ang binabanggit na tila tatlong "sabong" na nagtutunggalian: una, ang manggagawa sa asyenda at panginoong may lupa na amo nito; pangalawa, ang manggagawa at ang asawa't anak nito; at pangatlo, ang asawa't anak ng manggagawa at mga tama(w)o. Mahihiwatigan na lunan ang asyenda sa digmaan ng gahum na nakabatay sa kaniya-kaniyang interes. Ngunit, sa huling bahagi ng "Tamawo," masasabing tila nagtagumpay ang mga tama(w)o sa paghihiganti laban sa mga taong kumuha ng kristal na itlog. Bunsod ng pagkabasag at pagkamatay ng sanggol na tama(w)o sa itlog, hindi makokontento ang mga tama(w)o kung hindi ito mapapalitan ng isa ring bata. Sa pagtatapos ng kuwento, bilang kapalit ng sanggol na namatay, napilitang sumama ang bidang batang lalaki sa lupon ng mga tama(w)o. Mapapansin, sa bahaging ito, na tila nawala sa naratibo 
ng kuwento ang may-ari ng asyenda at nanatiling ang maliliit na tao sa loob ng espasyong ito ang siyang dumanas ng pagdurusa at paghihiganti. Kung susuriin, tila ang sistema pa rin ng asyenda ang nagwagi rito dahil maliliit na tao lamang at ang "tama(w)o" ang siyang naglaban at ang mga may hawak ng gahum ang siya pa ring nanatili sa kanilang mga pinanghahawakan.

Tila sumusunod sa hulma ng naratibo ng "Tamawo" (Monteverde, Monteverde, \& Somes, 2011) ang isang kuwento ni Adelina Gurrea, ang "La doncella que vivió tres vidas" (1943) mula sa aklat na Cuentos de Juana?. Itinatampok sa nakakuwadrong kuwento ang buhay ng labing-anim na taong gulang na si Pinang, na isinasalaysay mula sa punto de bista ng anak may-ari ng asyenda na si Juana. Sa naratibo ni Gurrea, maaaring hatiin sa tatlong bahagi ang buhay ni Pinang: sa loob ng asyenda, sa daigdig ng mga tama(w)o, at ang buhay nito matapos ang pagdukot. Maaaring basahin ang tatlong bahaging ito bilang mahahalagang pitak hindi lamang sa personal na buhay ni Pinang kundi maging sa bansa. Animo'y daluyan ng mismong personal na danas ang pambansang danas sa kuwento ni Gurrea, dahil na rin sa pagkakatulad at kaugnayan ng tatlong buhay ni Pinang sa tatlong mahahalagang panahon sa kasaysayan ng Pilipinas: prekolonyal, kolonyalismo sa ilalim ng mga Espanyol, at kolonyalismo sa ilalim ng mga Amerikano (Cruz-Lucero, 2013). Ngunit ang tama(w)o"sa kuwento ni Gurrea, tulad sa pelikula ni Somes, ay nagsususon-susong talinghaga: ang bayani sa mga sugidanon (epiko) at ang halimaw na mananakop; ang Sarili at ang Iba; at ang pagiging Iba ng Sarili (Cruz-Lucero, 2013, p. 123). Sa pagpapakahulugang ito, lumilitaw ang dalumat sa tama(w)o bilang sinematikong kaalamang-bayan at salaysay ng damdamin-balon na maituturing sa paglikha ng diyalektika at tambalan, sa pagitan ng diskurso sa bansa at rehiyon, na hindi matapos-tapos.

\section{Mga Salaysay at Daluyan Hinggil sa Bayan at Rehiyon}

Dalawang batis ang pinag-iigiban ng mga pelikula ni Somes na nag-uugnay sa dalumat ng aswang at tama(w)o na nakakawing sa diskurso ng bansa at rehiyon. Una, mababanaag na ang mga nilalang na itinampok ni Somes sa kaniyang mga pelikulang sinuri ay bahagi ng kaalamang-bayan, partikular na sa Visayas na kaniyang pinagmulan. Lantad sa pagtatampok ni Somes sa mga nilalang ang mga umiinog ditong idyoma at tekstura ng rehiyonmalayong komunidad, lumang paniniwala, atrasadong pamumuhay, at sistema ng asyenda. Mula sa unang batis na ito, sisilip ang pangalawang batis na pinagkukunan ng anyo at hugis ng mga pelikula ni Somes-ang pelikulang katatakutan. Bagama't lagi nang ikinakabit ang anyo ng pelikulang katatakutan sa mga tala at datos hinggil sa kaysaysayan ng pelikula sa Pilipinas, mahalagang bigyan ng diin ang landasin na maari nang basahin 
ang pelikulang katatakutan bilang daluyan ng mga agam-agam, sindak, at takot na nararanasan ng bansa (Tolentino, 2016). Sa puntong ito, kapansinpansin ang mga sinematikong pagpapakahulugan sa aswang at tama(w) o bilang lagusan ng mga salaysay ng agam-agam na kakabit ng diskurso hinggil sa "bayan" at "rehiyon."

Dagdag pa rito, sumisilip sa mga pelikulang sinuri ang kahulugang iniiwan ng paggamit nito sa anyong katatakutan, namamagitan at nagninilay ito sa prekolonyal at kolonyal na danas at kondisyon ng bansa. Ang anyong katatakutan ang siyang dumudulog sa sinematikong kahingian at estetika ng pelikula ngunit hinahayaan din nitong umusbong at umunlad ang tila proseso ng demonisasyong lumalaganap sa "katutubong sistema ng paniniwala" sa prekolonyal na daigdig.

Kung papansinin naman ang sinematikong pagharaya sa aswang at tama(w)o na tinatanaw bilang mga salaysay at daluyan ng damdamin ng bansa, mahalagang bigyan ng diin ang mga salik na umusbong mula sa mga pelikulang sinuri: una, hinaharaya ang bansa batay sa mito ng heograpikong aspekto nito na nagtatampok sa mga liblib na baryo at siyudad, wala nang labis, walang kulang; pangalawa, inilalarawan ang mga lunan sa mga rehiyon sa labas ng Maynila, lalo na ang maliliit na baryo bilang sityo ng karahasan at lagim, katakot-takot (dagdag pa ang paggamit ng anyo at kumbensiyon dito ng pelikulang katatakutan) lalo na't sa episodyo ng "Lihim ng San Joaquin" mula sa SRR 2K5 (Monteverde, Monteverde, \& Somes, 2005), ang mga aswang ay pinaniniwalaang nagmula sa Visayas at Mindanaw at nagtungo lamang sa Luzon upang doon itatag ang kanilang pinakahuling himpilan sa bansa; pangatlo, mahihiwatigan sa mga pelikulang sinuri ang paglikha ng espasyo at imahen ng "Ibang Pilipinas" na naghahayag ng kakaibang perspektiba ng buhay sa labas ng Sentro (Groyon, 2014, p. 194); at pangapat, nagbabago-bago ang kayarian at pagkakahabi ng mga naratibo ng pelikulang sinuri ukol sa danas ng "Ibang Pilipinas," kalimitang itinatampok ang mga paniniwala, tradisyon, at kultura sa laylayan ngunit kadalasan, nalulusaw ang mismong konteksto nito upang magbigay ng daan sa pagiging komersiyalisado ng pelikula; at panlima, may pag-aangkin sa pagiging Iba ng mga pelikulang sinuri, at ang pagiging Iba na ito ay tila naiangkop na rin sa dalumat ng kaniyang Sarili.

Lagpas sa nakamamanhid na kategorya ng malayang pelikula (independent cinema) at pangkomersiyal na pelikula (commercial/ mainstream cinema), maging ang pagbibigay ng hugis sa kung ano ang pelikulang rehiyonal at hindi, mababakás ang ilang binhi ng pagiging Iba ng mga sinuring pelikula ni Somes sa antas at anyo ng tekstura nito, bagama't nalusaw ang ilang batayang kaligiran at salik na pundasyon ng mismong danas dito. Kung tatanawin ang mga pelikula ni Somes sa hugpungan ng 
"loob" at "labas" - marahil sa dalumat ng loob ng Sentro at labas ng Sentrohigit na mas makabuluhang pagtuunan ng pansin ang "lalim" na binabanggit ng mga pelikula sa pamamagitan ng mga salaysay ng damdamin. Kung ang aswang at tama(w)o, bilang mga salaysay ng damdamin, ay nagpapahiwatig ng pagiging Iba lalo na sa nakararami, ito ang idinidiin ng pelikulang rehiyonal na nakikipagtalastasan sa pelikulang pambansa: ang pagiging Sarili para sa kaniyang Sarili ngunit Iba sa kaniyang Iba.

Kung patuloy na tinatanaw ang mga aswang at tama(w)o bilang mga nilalang na umiiral sa mga rehiyon bilang Iba sa Sarili ng Sentro, maaari itong tingnan sa punto-de-bista ng kahalagahan ng pagkakaiba-iba ng bawat pelikulang rehiyonal lalo na't mayroon ang bawat isa nito ng nagkakaibaibang danas sa iba-ibang batayan at kondisyong panlipunan, pangkultura, pampolitika, pang-ekonomiya, at pangkasaysayan. Nasa pagkakaibaibang ito ng mga pelikulang rehiyonal ang hinihintay na pagluluwal sa hinaharayang mga pelikulang pambansa, hindi lamang iisa kundi marami, na nagbabago-bago batay sa nagkakaiba-ibang interes, pananaw, at panahon. Mga pelikulang Pambansa na nag-iiba-iba ang pagpapakahulugan batay sa tumatanaw nito-sa punto de bista ng Iba at ka-Ibahan nito, Sarili at Sinasarili nito, anumang lente at kuwadro ang gamitin, sa anumang kulay at ilaw ito tanawin, saan mang lupalop na nahahagip ng nag-iiba-ibang estetika. 


\section{Mga Sanggunian}

Aguilar, F. (1997). Masonic myths and revolutionary feats in Negros Occidental. Journal of Southeast Asian Studies, 28(2), 285-300.

Aguilar, F. (1998). Clash of spirits: The history of power and sugar planter hegemony on a Visayan island. Ateneo de Manila University Press.

Alburo, E. K. (1994). El hijo disobediente. In B. Lumbera \& N. G. Tiongson (Eds.), CCP Encyclopedia of Philippine Art, Volume VIII, Philippine Film. Cultural Center of the Philippines.

Alcina, I. (2005). Historia de las islas de indios Bisayas, 1668. (C. Cobak \& L. Gutierrez, Trans.). UST Publishing House.

Almario, V. S.(Ed.). (2015). Hiyas ng tulang Tagalog. Komisyon sa Wikang Filipino.

Anderson, W. H. (2007). Colonial pathologies: American tropical medicine, race, and hygiene in the Philippines. Ateneo de Manila University Press.

Arguelles, R., Montelibano, M. M., Montelibano, R. (Producers), \& Somes, R.. (Director). 2008. Yanggaw [Motion picture]. Cinema Originals Film Productions.

Baes, G. B. (2011). A catechism on Capiz aswang phenomenon (For Catholic school students and teachers in Capiz) (Unpublished doctoral dissertation). De La Salle University, Manila, Philippines.

Barbaza, R. E.. (2017). An orosipon kan Bikolnon: Interrupting the Philippine nation. University of the Philippines Press.

Bautista, J.T. (2017). San Joaquin: Unseen Iloilo. Manila Times. https://www.manilatimes.net/san-joaquinunseen-iloilo/361020/

Bhabha, H. K. (1990). Nation and narration. Routledge.

Brownrigg, R. (2001). Who's who in the New Testament. Psychology Press.

Caballero, F. "Tuohan" \& Caballero-Castor, T. "Abyaran" . (2014). Tikum kadlum. Recorded \& Translated by Alicia P. Magos. University of the Philippines Press.

Calmerin, L.A., Kintanar, K. U., Samson-Martinez, M. (Producers), \& Somes, R.. (Director). (2012). Corazon: Ang unang aswang [Motion picture]. Skylight Film Productions.

Castro, J., A. Antonio, P. Melendez-Cruz, J. Mariano, \& J. Makasiar-Puno. (2009). Antolohiya ng mga panitikang ASEAN: Mga epiko ng Pilipinas. APO Productions Unit, Inc.

Castro, J.,A. Antonio, P. Melendez-Cruz, J. Mariano, \& J. Makasiar-Puno.. (1983). Anthology of ASEAN Literatures: Epics of the Philippines. Apo Production Unit, Inc.

Chakrabarty, D. (2000). Provincializing Europe: Postcolonial thought and historical difference. Princeton University Press.

Cole, F. C. (1913). The wild tribes of Davao district, Mindanao. Field Museum of Natural History.

Cruz-Lucero, R. (2013). "Gods, monsters, heroes, and tricksters in Adelina Gurrea's Cuentos de Juana." Kritika Kultura 2013, (20), 99-128.

Cruz-Lucero, R. (2007). The nation beyond Manila / Ang bayan sa labas ng Maynila. Quezon City, Ateneo de Manila University Press.

Cruz-Lucero, R.. \& Lumbera, B. (Eds.). (2001). Western Visayas literature: Basilio, a composo (p. 452). In Filipinos writing: Philippine literature from the regions. Anvil Publishing.

Dadole, J. O. (1986). The Talagbusao phenomenon : a study in religiosity among the Bukidnon (Unpublished masters). Xavier University, Cagayan de Oro City. 
De Loarca, M. (1582). Relacion de las Islas Filipinas. In J.A.R. Blair and E.H. Robertson (Eds), Philippine Islands, 1493-1898, vol. 5.

dela Cruz, K. (2010). Philippine new wave: This is not a film movement. Quezon City: Noel D. Ferrer and MOVFest \& Instamatic Writings.

Demetrio, F. (1969). The enkanto belief: An essay in interpretation Philippine Studies Journal, 17(3), 556596.

Fabian, J. (1983). Time and the other: How anthropology makes its objects. Columbia University Press.

Groyon, V. G. (2014). Cinemarehiyon 2009. In R. Cruz Lucero, J. Chua, \& R. Tolentino (Eds.), A reader in Philippine film: history and criticism, essays in honor of Nicanor G. Tiongson. University of the Philippines Press.

Guieb, E. R. III. (2009). Taksonomiya ng sineng Filipino: Mga kinagisnan at umuusbong na genre o anyo, at mga paglihis sa mga kumbensyon. In Young Critics Circle Film Desk (Ed.), Sining ng sineng Filipino (pp. 53-108). UP Sentro ng Wikang Filipino.

Gurrea, A. (1943). Cuentos de Juana: Narraciones malayas de las Islas Filipinas. Madrid: Imprenta de Prensa Española.

Jocano, F. L. 2000. Introduction. Hinilawod:Adventures of humadapnon arangban I. Chanted by Hugan-an, Recorded and Translated by F. Landa Jocano. Punlad Research House, Inc.

Kotzathanasis, P. (2018). Film review: We will not die tonight (2018) by Richard Somes. Asian movie pulse 2018. https://asianmoviepulse.com/2018/06/film-review-we-will-not-die-tonight-2018-byrichard-somes/

Lim, B. C. (2011). Translating time: Cinema, the fantastic, and temporal critique. Ateneo de Manila University Press.

Lumbera, B. (2013). Peque Gallaga: The complete cinema artist in twilight. In N.G. Tiongson (Ed.), The Urian anthology 2000-2009. The rise of the Philippines new wave indie film: Film artciles, reviews, and interviews of the anunuri ng Pelikulang Pilipino on the Filipino cinema 2000-2009 (pp. 486-493). University of the Philippines Press.

Lynch, F. X. (2004). Ang mga asuwang: A Bicol belief. In A. A. Yengoyan \& P. Q. Makil (Eds.), Philippine society and the individual: Selected essays of Frank Lynch, 1949-1976 (pp. 184-206). Institute of Philippine Culture, Ateneo de Manila University Press.

Magos, A. P. (2005). The aswang: A cultural and historical reality?" Sinadya Souvenir Program. Roxas City, DILG.

Magos, A. P. (1992). The enduring Ma-aram tradition: An ethnography of a Kinaray-a village in Antique. New Day Publishers.

Matilac, R., J. Bejarin, \& R. Jocson. (1994). Ifugao. In B. Lumbera \& N. G. Tiongson (Eds.), CCP encyclopedia of Philippine art, Volume VIII, Philippine film (p. 165). Cultural Center of the Philippines.

Meñez, H. Q. (1999). The Viscera-Sucker and the Politics of Gender. In H. Meñez (Ed.), Explorations in Philippine folklore (pp. 86-94). Ateneo de Manila University Press.

Mojares, R. B. (2002). Waiting for Mariang Makiling. In R. B. Mojares (Ed.), Waiting for Mariang Makiling (pp. 1-19). Ateneo de Manila University Press.

Monteverde, L., Monteverde R. (Producers), \& Somes, R. (Director). (2005). Shake, rattle, and Roll 2 k5 [Motion picture]. Regal Films. 
Monteverde, L., Monteverde R. (Producers), \& Somes, R. (Director). (2011). Shake, Rattle, and Roll 13 [Motion picture]. Regal Films.

Nancy, J. L. (1991). The inoperative community. Minneapolis: University of Minnesota Press.

Pertierra, R. (1983). Viscera-suckers and female sociality: The Philippine asuang. Philippine Studies Journal, 31(3), 319-337.

Rafael, V. (1988). Contracting colonialism: Translation and christian conversion in Tagalog society under early Spanish rule. Ateneo de Manila University Press.

Ramos, M. (1971). Creatures of Philippine lower mythology. University of the Philippines Press.

Santiago, L. Q. (1997). Sa ngalan ng ina: Sandaang taon ng tulang feminista sa Pilipinas, 1889-1989. University of the Philippines Press.

Santos, R. B. (1994). Ang lipunan at kasaysayan sa urbana at feliza. (Unpublished masters thesis). University of the Philippines Diliman.

Tianero, R. C., OMI. (2002). Direct violence and christianity among Manobo converts. (Unpublished masters thesis). Ateneo de Manila University, Philippines.

Tiongson, N. G. (2013). The rise of the Philippine new wave independent film. In N. G. Tiongson (Ed.). The urian anthology 2000-2009 (pp. 2-45). University of the Philippines Press.

Tolentino, R. B. (2016). Shake, rattle, and roll horror franchise and the specter of nation-formation in the Philippines." Humanities Diliman 13(1),134-152.

Zhang, J. (2005). Filmic folklore and Chinese cultural identity. Western Folklore, 64(3-4), 263-280. 


\section{Endnotes}

${ }^{1}$ Maaari ding basahin ang "Enteng Kabisote as Filmic Folklore," isang kabanata sa librong The End of National Cinema ni Patrick Campos. Pinag-aralan ni Campos ang serye ng mga pelikulang Enteng Kabisote bilang "sinematikong kaalamang-bayan" sa gitna ng nagdidigmaang daigdig ng kultura, sining, at komersiyalismo.

2 Sa pagpapayaman ng diskusyon hinggil sa "poklorikong pelikula" (folkloric film), maaaring tingnan ang mga naunang pag-aaral na naging gabay ni Juwen Zhang sa kaniyang pormulasyon ng "sinematikong kaalamang-bayan" (filmic folklore):"The Folkloric Film: Definition and Methodology, Texts and Contexts" mula sa Documenting Ourselves: Film, Video, and Culture ni Sharon R. Sherman (2007); at ang antolohiyang Folklore/Cinema: Popular Film as Vernacular Culture na inedit nina Sharon R. Sherman at Mikel J. Koven (2007).

${ }^{3}$ Sa bahaging ito, gagamitin ko ang "Panay Bukidnon" sa halip na "Sulod" bilang katawagan sa grupo na siyang lumilikha at kumakatha ng mga Sugidanon sa Panay. Masalimuot na usapin ang katawagang "Sulod" dahil marami ang nagpapalagay na si Jocano lamang ang gumamit nito bilang pantawag sa mga Panay Bukidnon. Sa Sugboanong Binisaya, ang "sulod" ay nangangahulugang "loob." Marahil, ginamit ito ni Jocano bilang katawagan sa grupo ng tao na nakatira sa "loob" ng bundok.

${ }^{4}$ Sa konteksto ng mga sugidanon ng Panay Bukidnon, ang aswang o tagubalbal ay isang nilalang na maaari ding isang "buyong," isang marangal na tao sa komunidad na kilala rin sa pagiging magiting na mandirigma na nakatikim o nakakain na ng laman-loob ng tao" (akin ang salin) (Magos 2014, 11).

${ }^{5}$ Mayroon akong suspetsa na ang binabanggit na Demetrio na mga "tumao" mula sa Cagayan de Oro ay hindi naiiba at kaugnay ng "tamawo" na bahagi ng kinagisnang sistema ng paniniwala ng mga llonggo. Ngunit kinakailangan pa ang empirikal at masusing pananaliksik upang mapatunayan at mapatibay ang sapantahang ito.

${ }^{6}$ Sa bahaging ito, malay akong gagamitin ang problematikong termino ng "espiritu" bilang pantumbas sa "spirits" na binabanggit ni Filomeno Aguilar. Sa puntong ito, mahalaga ring sipatin kung matatawag nga bang "espiritu" ang mga "tamawo" at "tanod" lalo na't kalakip ng katawagang "espiritu" ang Kanluraning pagpapakahulugan dito. Mahalaga ring sipatin na sa imahinasyong llonggo, ang mga "babaylan" o "babaylanes" o "ma-aram" ay may iba't iba pang tungkulin sa pamayanan na hindi lamang limitado sa espirituwal na gawi. Nakaaatang din sa kanilang tungkulin ang pagpaplano sa ekonomiya ng komunidad, pagiging tagapagpapayapa, at maging tagapayo sa mga digmaan. Maaaring tingnan ang etnograpiya ni Alicia Magos hinggil dito na may pamagat na The Enduring Ma-aram Tradition: An Ethnography of a Kinaray-a Village in Antique (1992).

${ }^{7}$ Isang mahalagang manunulat si Adelina Gurrea na tila kinaligtaan sa ilang tala at datos ng kasaysayang pampanitikan sa Pilipinas. May aklat si Gurrea, ang Cuentos de Juana (1943), na nagtatampok sa danas at kaalamang-bayan ng iba-ibang nilalang tulad ng tao, "tama(w)o," atbp., sa kanilang asyenda sa La Carlota sa Isla ng Negros kung saan tanaw ang Bundok Kanlaon. Maaaring balikan ang sanaysay ni Rosario Cruz-Lucero na "Gods, Monsters, Heroes, and tricksters in Adelina Gurrea's Cuentos de Juana," nalathala sa Kritika Kultura 20 (2013): pp. 99-128, para sa mas malalim na pag-unawa sa buhay, haraya, at akda ni Adelina Gurrea. Kalakip ng sanaysay ang ilan pang kritikal na pagsusuri sa kaalamang-bayan na nakapaloob sa kuwento ni Gurrea tulad ng dalumat sa "tama(w)o." 


\section{Grant Support Details}

Author Contributions: All research activities and writing were done by J. J. F. Quintos. The author has read and agreed to the published version of the manuscript.

Funding: The author received no specific funding for this work.

Conflict of Interest: The author declares no conflict of interest.

\section{About the Author}

JAY JOMAR F. QUINTIOS is a faculty member at the University of the Philippines Diliman. With cinema studies, folk studies, and Philippine literature as his research interests, his works have already appeared in various national and international publications. He is also an independent filmmaker. (corresponding email: jfquintos@up.edu.ph) 
